\title{
Use of Artificial Neural Networks to Predict Fuel Consumption on the Basis of Technical Parameters of Vehicles
}

\author{
Jarosław Ziółkowski, Mateusz Oszczypała ${ }^{(D)}$, Jerzy Małachowski *(D) and Joanna Szkutnik-Rogoż
}

Citation: Ziółkowski, J.; Oszczypała, M.; Małachowski, J.; Szkutnik-Rogoż, J. Use of Artificial Neural Networks to Predict Fuel Consumption on the Basis of Technical Parameters of Vehicles. Energies 2021, 14, 2639. https://doi.org/10.3390/en14092639

Academic Editor: María del Carmen Pegalajar Jiménez

Received: 24 March 2021

Accepted: 29 April 2021

Published: 5 May 2021

Publisher's Note: MDPI stays neutral with regard to jurisdictional claims in published maps and institutional affiliations.

Copyright: (c) 2021 by the authors. Licensee MDPI, Basel, Switzerland. This article is an open access article distributed under the terms and conditions of the Creative Commons Attribution (CC BY) license (https:/ / creativecommons.org/licenses/by/ $4.0 /)$.
Faculty of Mechanical Engineering, Institute of Mechanics and Computational Engineering, Military University of Technology, gen. Sylwestra Kaliskiego 2, 00-908 Warsaw, Poland; jaroslaw.ziolkowski@wat.edu.pl (J.Z.); mateusz.oszczypala@wat.edu.pl (M.O.); joanna.szkutnik@wat.edu.pl (J.S.-R.)

* Correspondence: jerzy.malachowski@wat.edu.pl

\begin{abstract}
This publication presents a multi-faceted analysis of the fuel consumption of motor vehicles and the way human impacts the environment, with a particular emphasis on the passenger cars. The adopted research methodology is based on the use of artificial neural networks in order to create a predictive model on the basis of which fuel consumption of motor vehicles can be determined. A database containing 1750 records, being a set of information on vehicles manufactured in last decade, was used in the process of training the artificial neural networks. The MLP (Multi-Layer Perceptron) 22-10-3 network has been selected from the created neural networks, which was further subjected to an analysis. In order to determine if the predicted values match the real values, the linear Pearson correlation coefficient $r$ and coefficient of determination $R^{2}$ were used. For the MLP 22-10-3 neural network, the calculated coefficient $r$ was within range 0.93-0.95, while the coefficient of determination $R^{2}$ assumed a satisfactory value of more than 0.98 . Furthermore, a sensitivity analysis of the predictive model was performed, determining the influence of each input variable on prediction accuracy. Then, a neural network with a reduced number of neurons in the input layer (MLP-20-10-3) was built, retaining a quantity of the hidden and output neurons and the activation functions of the individual layers. The MLP 20-10-3 neural network uses similar values of the $r$ and $R^{2}$ coefficients as the MLP 22-10-3 neural network. For the evaluation of both neural networks, the measures of the ex post prediction errors were used. Depending on the predicted variable, the MAPE errors for the validation sets reached satisfactory values in the range of 5-8\% for MLP 22-10-3 and 6-10\% for MLP 20-10-3 neural network, respectively. The prediction tool described is intended for the design of passenger cars equipped with internal combustion engines.
\end{abstract}

Keywords: artificial neural networks; prediction; fuel consumption

\section{Introduction}

The fuel consumption of motor vehicles powered by internal combustion engines unchangeably constitutes an essential issue in forming not only the development trends of the automotive industry, but is also an important factor in the economics of transport [1-4]. On the basis of the analysis of a set of the research papers, this problem is certainly a complex issue and must be considered as a many-faceted one. In logistics and business economics, fuel consumption generates costs relating to the transport of materials and products, which are an important component of a company's expenditure [5]. From the viewpoint of enterprise economics, an underlying direction of an optimisation is to minimise the costs linked to fuel consumption [6-8].

Climate change and the degradation of the natural environment, related to the human and industrial activities, are an aetiology of an ecological approach to the processes of the consumption of petroleum-based fuels in vehicles powered by internal combustion engines [9-11]. The manufacturers from the automotive industry are obliged to fulfil the more and more strict EURO emission standards, which are applicable within the European Union. The assumption of EURO standards consists in protecting the natural 
environment by limiting the emission of nitrogen oxides, hydrocarbons, carbon oxides and particulates. The objective of the successive tightening up of the exhaust emission standards is to reduce the air pollution caused by vehicles powered by internal combustion engines, especially in large urban agglomerations [12]. According to Regulation (EU) 2019/631 of the European Parliament and of the Council, the fleetwide $\mathrm{CO}_{2}$ Emission Targets for new passenger cars are $95 \mathrm{~g} / \mathrm{km}$ (if we want to compare the previous standards in years 2015-2020, it was on the level of $130 \mathrm{~g} / \mathrm{km}$ ). The supply and exhaust systems of the internal combustion engines were the subject of a large amount of research concerning the decrease in fuel consumption and the emission of harmful chemicals [1,13-16]. In the case of fuel consumption, optimisation and the reduction in the emission of harmful chemical compounds by vehicles powered by a hybrid powertrain, the genetic algorithms have already been implemented, lowering the values of the optimised variables by over $40 \%$ [17].

In the literature, one of the current research problem is the impact of the technical solutions and road conditions on fuel consumption. The publication by C. D. Rakopoulos et al. [18] contains the influence analysis of vegetable-origin additives to diesel oil on the volumetric fuel consumption in a direct injection diesel engine. Relationships between road conditions, driving style and combustion in buses and passenger cars providing taxi services were considered in the research papers authored by Jinghui Wang et al. [3] and Ying Yao et al. [19], respectively. In an article by P. Typaldos et al. [20] attempts were made to determine the conditions and kinematic trajectories of the vehicle that could lead to a minimisation of fuel consumption according to the principles of eco-driving. In the abovementioned papers, the statistical and analytical methods were used to analyse the relationships between the variables under consideration.

Artificial Neural Networks (ANNs) as a research tool for estimating fuel consumption were used in many published scientific studies. They were applied in modelling problems for aircrafts [21], sea vessels [22-27], mining trucks [28] and agricultural tractors [29]. In publication [30], the authors implemented artificial neural networks to determine a relationship between the engine velocity and torque and the actual fuel consumption while driving trucks, and the achieved results were encumbered with mean percentage errors at a low level (below 5\%). The advantage of this solution was a high accuracy of an estimation of the values of the predicted variables. In the case of passenger cars, research studies where the ANN was used to search for the relations between technical parameters and conditions of the use and fuel consumption were found [31]. In publication [32], the authors used artificial neural networks to predict fuel consumption and torque generated by a spark-ignition engine, obtaining a mean absolute percentage error (MAPE) under 3\%.

The research papers presented above were focused on the search for the relationships between the studied variables in a strictly defined vehicle, machine or another technical object. In the paper authored by Zargarnezhad S. et al. [8] an attempt was made to use neural networks in fuel consumption prediction on a database of 51 Toyota and Hyundai vehicles. A network combining five input and one output variables was proposed. On the basis of the correlation coefficient values of training, testing and validation sets, ranging from 0.94-0.99, with mean square error (MSE) at a level not exceeding 0.6 , an acceptability of prediction was determined. Table 1 presents the results of the selected studies concerning the research problems related to fuel consumption, engine performance and emission of the chemical compounds generated during the fuel combustion, to which artificial neural networks were applied. Among these results, the analyses focused on the area of research related to engine performance, fuel consumption and the emissions of chemical compounds from compression ignition engines. A common property of most of the analyses compared is the high accuracy of the developed predictive models, where $M A P E$ errors fail to exceed $5 \%$. 
Table 1. Comparative analysis of research results obtained in the selected research papers.

\begin{tabular}{|c|c|c|c|c|}
\hline Research Area & Structure of ANNs & Predicted Variables & Results & Publication \\
\hline \multirow{3}{*}{$\begin{array}{l}\text { Fuel consumption of } \\
\text { many vehicles }\end{array}$} & $5-17-17-1$ & Fuel consumption & $\begin{array}{c}R: 0.94-0.99 \\
M S E<0.6\end{array}$ & [8] \\
\hline & $\begin{array}{c}3-128-1 \\
3-64-64-1 \\
3-(4 \times 32)-1 \\
3-(8 \times 16)-1\end{array}$ & Fuel consumption & $R^{2}: 0.72-0.78$ & [33] \\
\hline & $\begin{array}{l}9-4-1 \\
9-6-1 \\
9-8-1 \\
9-10-1 \\
9-12-1\end{array}$ & Fuel consumption & $R=0.82$ & {$[34]$} \\
\hline \multirow{6}{*}{ Diesel engine } & $\begin{array}{l}4-8-2 \\
4-14-3 \\
4-13-5\end{array}$ & $\begin{array}{c}\text { BSEC (Brake Specific Energy } \\
\text { Consumption) } \\
\text { BTE (Brake Thermal Efficiency) } \\
\text { ID (Ignition Delay) } \\
\text { CD (Combustion Duration) } \\
\text { CPP (Cylinder Peak Pressure) } \\
\text { Exhaust emission }\left(\mathrm{CO}, \mathrm{CO}_{2}, \mathrm{UBHC},\right. \\
\left.\mathrm{NO}_{\mathrm{x}}, \mathrm{Smoke}^{\mathrm{S}}\right)\end{array}$ & $\begin{array}{c}R^{2}>0.98 \\
R: 0.95-1.00 \\
M A P E<5 \%\end{array}$ & [35] \\
\hline & $3-9-5$ & $\begin{array}{l}\text { Brake thermal efficiency } \\
\text { BSEC } \\
\text { Exhaust emission }\left(\mathrm{NO}_{\mathrm{x}}, \mathrm{UBHC}, \mathrm{CO}\right)\end{array}$ & $\begin{array}{c}R^{2}>0.99 \\
M A P E<4 \%\end{array}$ & [36] \\
\hline & $3-7-2$ & $\begin{array}{l}\text { Fuel consumption } \\
\text { Exhaust temperature }\end{array}$ & $M A P E<3 \%$ & [37] \\
\hline & $4-10-10-5$ & $\begin{array}{c}\text { BSEC } \\
\text { BTE } \\
\text { Exhaust emission }\left(\mathrm{CO}_{2}, \mathrm{NO}_{\mathrm{x}}\right) \\
\text { PM (Particulate matter) }\end{array}$ & $\begin{array}{c}R^{2}>0.98 \\
M A P E<5 \%\end{array}$ & [38] \\
\hline & $\begin{array}{c}4-2-7 \\
4-4-7 \\
4-6-7 \\
4-8-7 \\
4-10-7\end{array}$ & $\begin{array}{c}\text { BSFC (Brake Specific Fuel } \\
\text { Consumption) } \\
\text { BTE } \\
\text { Exhaust temperature } \\
\text { Exhaust emission }\left(\mathrm{CO}, \mathrm{HC}, \mathrm{NO}_{\mathrm{x}}\right) \\
\text { Smoke }\end{array}$ & $\begin{array}{l}R: 0.97-0.99 \\
M S E=0.06\end{array}$ & [39] \\
\hline & $3-8-9$ & $\begin{array}{c}\text { Exhaust gas temperature } \\
\text { BSFC } \\
\text { Power } \\
\text { Torque } \\
\text { Smoke } \\
\text { Exhaust emission }\left(\mathrm{CO}, \mathrm{CO}_{2}, \mathrm{HC}\right. \\
\left.\mathrm{NO}_{\mathrm{X}}\right) \\
\end{array}$ & $R^{2}: 0.80-0.96$ & [40] \\
\hline Gasoline engine & $\begin{array}{l}4-13-1 \\
4-15-1\end{array}$ & $\begin{array}{c}\text { Torque } \\
\text { BSFC }\end{array}$ & $\begin{array}{c}R>0.98 \\
M A P E<3 \%\end{array}$ & [32] \\
\hline \multirow[t]{2}{*}{ Stirling engine } & $\begin{array}{c}4-\mathrm{H}-2 \\
(\mathrm{H}=\{3,4,5, \ldots, 13\})\end{array}$ & $\begin{array}{l}\text { Power } \\
\text { Torque }\end{array}$ & $R^{2}>0.97$ & [41] \\
\hline & $3-10-1$ & Power & $R^{2}>0.97$ & [42] \\
\hline $\begin{array}{l}\text { HCNG (hydrogen } \\
\text { enriched compressed } \\
\text { natural gas) engine }\end{array}$ & $\begin{array}{c}4-\mathrm{H}-1 \\
(\mathrm{H}=\{2,4,6, \ldots, 30\})\end{array}$ & $\begin{array}{c}\text { BSFC } \\
\text { Torque } \\
\text { Exhaust emission }\left(\mathrm{NO}_{x}, \mathrm{CO}, \mathrm{THC},\right. \\
\left.\mathrm{CH}_{4}\right)\end{array}$ & R: 0.79-1.00 & [43] \\
\hline Electric vehicles & $5-5-1$ & Energy consumption & $\begin{array}{c}R=0.81 \\
M A P E<5 \%\end{array}$ & {$[44]$} \\
\hline
\end{tabular}


The essence and the originality of this study is the determination of the synergistic impact of many technical parameters on fuel consumption for a broad range of the motor vehicles-modern passenger cars. The effect of such an approach is the development of a general predictive model for a prediction of fuel consumption. In this study, fuel consumption corresponding to the operating environment of the vehicle is adopted, as reflected by three predictor variables (city, motorway and mixed cycle). The outcomes of the formerly analysed research papers give a opportunity of artificial neural networks application as tools to develop predictive models. The use of artificial neural networks allows for conducting an effective analysis of a very large quantity of the empirical data. Contrary to the former research, the authors of the publication considered a broad range of passenger cars featuring different technical parameters. This paper constitutes a more generalised approach in comparison to the previously published predictive models based on artificial neural networks.

\section{Materials and Methods}

Artificial Neural Networks (ANNs) constitute an artificial intelligence tool, a method of data analysis that was widely used as an alternative to the traditional analytical methods. The objective of their use is to create a time-effective and accurate predictive model for the objects or phenomena under investigation [45]. The construction of the artificial neural network is modelled after the human brain, and for this reason, it is composed of neurons and synaptic pathways occurring between them. Each neuron may receive sets of information reflected by a value of a quantity of the variables, but only one piece of information represented by the value of one variable is the output [46]. Among the various types of artificial neural networks, MLP (Multi-Layer Perceptron) networks are the most prevalent and most commonly used. They consist of neurons divided into couple layers: input, hidden (one or more) and output. High accuracy of the predictive models based on MLP networks induced the authors of this research to use this type of artificial neural network to predict fuel consumption.

Studies dedicated to the use of artificial neural networks for prediction of fuel consumption were divided into the following stages of implementation:

- Selecting the technical parameters having a significant impact on the quantity of fuel consumption;

- Developing a database for the neural network learning process;

- Creating a set of neural networks and selecting the best of them;

- Calculating a correlation and determining the coefficients and carrying out a sensitivity analysis in respect of the input variables;

- Making an attempt to simplify the predictive model—an elimination of the input variables for which the sensitivity coefficient takes values less than or is equal to 1.0;

- Creating a new set of neural networks from a reduced database and selecting the best of them;

- Calculating the correlation and determining the coefficients, as well as performing a sensitivity analysis of the input variables for the reduced model;

- Comparing and evaluating an acceptability of the predictive models on the basis of the values of the ex post prediction error measures.

In Figure 1 the proprietary algorithm of using artificial neural networks to create a predictive model, according to the methodology described above, is shown. 


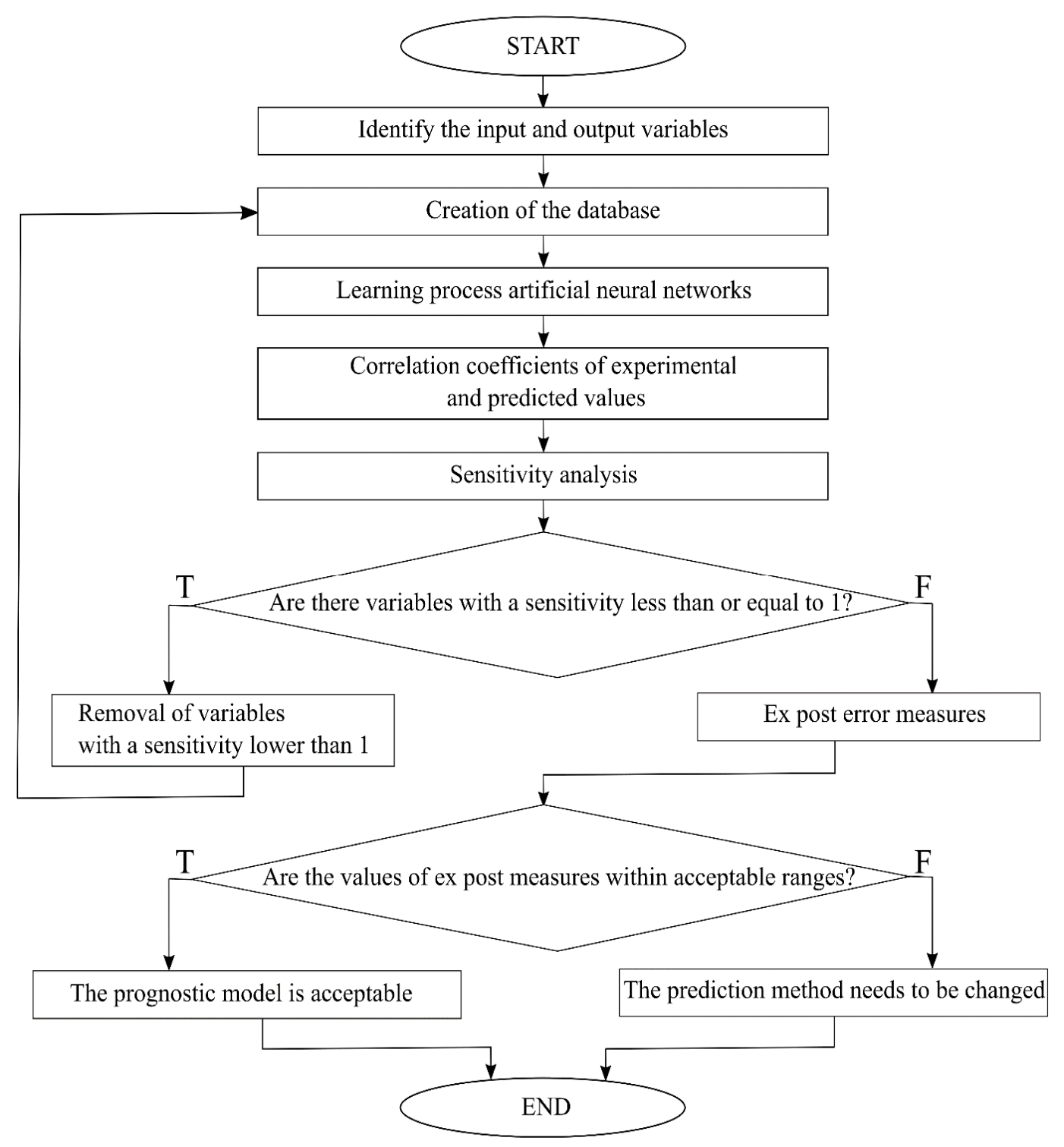

Figure 1. The concept of creating a prognostic model using ANNs.

\subsection{Identification of the Input and Output Variables}

The impact of the design solutions and technical parameters of the vehicles on fuel consumption was repeatedly analysed in the earlier studies carried out by other researchers. A significant relation between displacement capacity, vehicle weight, number of cylinders, number of valves and fuel consumption were presented in the paper by Zargarnezhad et al. [8]. On the basis of the literature analysis, a set of input and output variables for further studies was determined and it is presented in Table 2. It contains 12 input variables (7 quantitative and 5 qualitative) and 3 output variables. In the case of quantitative variables, a system of units was defined, while in the case of the individual qualitative variables, sets of admissible nominal values were assigned. 
Table 2. List of the input and output variables.

\begin{tabular}{|c|c|c|c|c|}
\hline Type & Jariables & Name of Variable & Designation & (Unit)/Nominal Values \\
\hline \multirow{22}{*}{ Input } & \multirow{7}{*}{ Quantitative } & Cubic capacity & $D_{E}$ & $\left(\mathrm{~cm}^{3}\right)$ \\
\hline & & Quantity of cylinders & $N_{C}$ & (unitless) \\
\hline & & Quantity of valves & $N_{V}$ & (unitless) \\
\hline & & Maximum power & $P_{\text {MAX }}$ & $(\mathrm{kW})$ \\
\hline & & Maximum torque & $T_{\text {MAX }}$ & $(\mathrm{Nm})$ \\
\hline & & Compression rate & $C_{R}$ & (unitless) \\
\hline & & Kerb weight of vehicle & $W_{V}$ & $(\mathrm{~kg})$ \\
\hline & \multirow{15}{*}{ Qualitative } & \multirow{4}{*}{ Type of engine } & \multirow{4}{*}{$E_{T}$} & Gasoline $\left(E_{T 1}\right)$ \\
\hline & & & & Diesel $\left(E_{T 2}\right)$ \\
\hline & & & & Hybrid: gasoline + electric $\left(E_{T 3}\right)$ \\
\hline & & & & Hybrid: diesel + electric $\left(E_{T 4}\right)$ \\
\hline & & \multirow{2}{*}{ Fuel injection } & \multirow{2}{*}{$F_{I}$} & Indirect $\left(F_{I 1}\right)$ \\
\hline & & & & $\operatorname{Direct}\left(F_{I 2}\right)$ \\
\hline & & \multirow{4}{*}{ Type of charge } & \multirow{4}{*}{$B_{T}$} & Naturally aspirated $\left(B_{T 1}\right)$ \\
\hline & & & & Turbocharger $\left(B_{T 2}\right)$ \\
\hline & & & & Biturbo $\left(B_{T 3}\right)$ \\
\hline & & & & Compressor $\left(B_{T 4}\right)$ \\
\hline & & \multirow{2}{*}{ Gearbox } & \multirow{2}{*}{$T_{G}$} & Manual $\left(T_{G 1}\right)$ \\
\hline & & & & Automatic $\left(T_{G 2}\right)$ \\
\hline & & \multirow{3}{*}{ Drivetrain } & \multirow{3}{*}{$D_{T}$} & $\operatorname{FWD}\left(D_{T 1}\right)$ \\
\hline & & & & $\operatorname{RWD}\left(D_{T 2}\right)$ \\
\hline & & & & $\operatorname{AWD}\left(D_{T 3}\right)$ \\
\hline \multirow{3}{*}{ Output } & \multirow{3}{*}{ Quantitative } & Fuel consumption in the urban cycle & $F C_{U}$ & $(1 / 100$ km) \\
\hline & & Fuel consumption in the extraurban cycle & $F C_{H}$ & $(1 / 100 \mathrm{~km})$ \\
\hline & & Fuel consumption in the mixed cycle & $F C_{M}$ & $(1 / 100 \mathrm{~km})$ \\
\hline
\end{tabular}

\subsection{Correlation Coefficients}

For the purposes of evaluation of the matching between predicted and real values of $F C_{U}, F C_{H}$ and $F C_{M}$ variables, the commonly used Pearson correlation coefficients $r$ [41,47-49] and the coefficient of determination $R^{2}[35,36,38,42]$ were employed. Pearson correlation coefficient is used to evaluate the level of linear relationship between the variables. It takes values from range $[-1 ; 1]$, where values close to 1 mean a positive dependence, close to -1 mean a negative dependence, and 0 means no linear dependence. The coefficient of determination $R^{2}$ takes values from the range [0;1]. The relationships enabling the calculation of values of coefficients $r$ and $R^{2}$ are presented using the Equations (1) and (2), adjusting them to the needs of carried-out research:

$$
r=\frac{\sum_{i=1}^{n}\left(E F C_{i}-\overline{E F C}\right) \times\left(P F C_{i}-\overline{P F C}\right)}{\sqrt{\sum_{i=1}^{n}\left(E F C_{i}-\overline{E F C}\right)^{2} \sum_{i=1}^{n}\left(P F C_{i}-\overline{P F C}\right)^{2}}},
$$




$$
R^{2}=1-\frac{\sum_{i=1}^{n}\left(P F C_{i}-E F C_{i}\right)^{2}}{\sum_{i=1}^{n} E F C_{i}^{2}},
$$

where: $E F C_{i}$ - experimental fuel consumption value for vehicle $i, P F C_{i}-$ predicted fuel consumption value for vehicle $i$ and $n$-number of records.

\subsection{Sensitivity Analysis}

A sensitivity analysis in the neural networks is used to determine the impact of individual input variables on predicted values of output variables [50,51]. The indicator used to determine the sensitivity of the predictive model to the values of the individual input variables is the coefficient $W_{j}[52,53]$ calculated according to formula (3):

$$
W_{j}=\frac{M S E_{j}}{M S E},
$$

where: $W_{j}$-sensitivity coefficient of the model to variable $j, M S E$ - mean squared error of the model prediction with all input variables and $M S E_{j}$ - mean squared error of the model prediction without the variable $j$.

If the coefficient $W_{j}$ takes a value equal to or less than 1 , then there are presumptions to eliminate variable $\mathrm{j}$ from the model while maintaining a current or higher accuracy of the predictive model [52].

\subsection{Prediction Errors}

A significant element of the result analysis of the use of artificial neural networks to predict fuel consumption is an evaluation of the admissibility of the predictions received as a result of the implementation of a given predictive model. In the literature [54,55], ex post errors are commonly used to analyse the accuracy of a prediction. The most frequently used measures of the prediction errors are presented below, along with the dependencies adjusted to the essence of the research problem [21,56-58]:

- Mean squared error (MSE):

$$
M S E=\frac{1}{n} \sum_{i=1}^{n}\left(E F C_{i}-P F C_{i}\right)^{2},
$$

- $\quad$ Root mean squared error (RMSE):

$$
R M S E=\sqrt{\frac{1}{n} \sum_{i=1}^{n}\left(E F C_{i}-P F C_{i}\right)^{2}},
$$

- Mean absolute percentage error (MAPE):

$$
M A P E=\frac{1}{n} \sum_{i=1}^{n}\left|\frac{E F C_{i}-P F C_{i}}{E F C_{i}}\right| \times 100 \% .
$$

\subsection{Database}

Artificial neural networks need a lot of data to conduct the learning process. For this purpose, a real database of 1750 records was established. The basis for its creation was data from the automotive industry, describing the technical parameters and experimentally determined quantities of fuel consumption in compliance with declarations made by manufacturers. The data concerns passenger cars manufactured all across the world during the years 2010-2020. The values of the fuel consumption variables were determined according to the NEDC (New European Driving Cycle) and the WLTP (Worldwide Harmonised Light Vehicles Test Procedure) tests [33,59-63]. 
The database contains a set of the vehicles featuring very different technical parameters and design solutions. The essence of this approach is to search for the universal relationships between the analysed variables for a broad range of the technical objects. Table 3 presents values obtained from the statistical analysis of the quantitative variables (input and output) from the developed database.

Table 3. Statistics on the quantitative variables.

\begin{tabular}{|c|c|c|c|c|c|}
\hline Variable & Mean & Median & Min. & Max. & SD \\
\hline Cubic capacity $D_{E}\left(\mathrm{~cm}^{3}\right)$ & 2096.00 & 1984 & 799 & 6299 & 831.36 \\
\hline Quantity of cylinders $N_{C}$ & 4.48 & 4 & 2 & 12 & 1.18 \\
\hline Quantity of valves $N_{V}$ & 17.38 & 16 & 6 & 48 & 5.15 \\
\hline Max. power $P_{M A X}(\mathrm{~kW})$ & 132.86 & 119.3 & 40.3 & 469.8 & 65.22 \\
\hline Max. torque $T_{M A X}(\mathrm{Nm})$ & 311.77 & 305.0 & 88.0 & 1000.0 & 135.55 \\
\hline Compression rate $C_{R}$ & 13.23 & 11.30 & 8.20 & 19.50 & 3.25 \\
\hline Kerb weight of vehicle $W_{V}(\mathrm{~kg})$ & 1463.70 & 1450.0 & 750.0 & 2656.0 & 294.14 \\
\hline Fuel consumption in the urban cycle $F C_{U}(1 / 100 \mathrm{~km})$ & 8.47 & 7.8 & 3.3 & 23.4 & 3.06 \\
\hline Fuel consumption in the extraurban cycle $F C_{H}(1 / 100 \mathrm{~km})$ & 5.37 & 5.1 & 3.0 & 13.7 & 1.35 \\
\hline Fuel consumption in the mixed cycle $F C_{M}(1 / 100 \mathrm{~km})$ & 6.51 & 6.1 & 3.2 & 17.0 & 1.94 \\
\hline
\end{tabular}

The Pearson correlation coefficients between individual input variables presented in Table 4 do not take values close enough to 1 to allow for the elimination of one of pair of correlated variables.

Table 4. Values of the correlation coefficient $r$ between quantitative input variables.

\begin{tabular}{cccccccc}
\hline Variable & $\boldsymbol{D}_{\boldsymbol{E}}$ & $\boldsymbol{N}_{\boldsymbol{C}}$ & $\boldsymbol{N}_{\boldsymbol{V}}$ & $\boldsymbol{P}_{\mathbf{M A X}}$ & $\boldsymbol{T}_{\boldsymbol{M A X}}$ & $\boldsymbol{C}_{\boldsymbol{R}}$ & $\boldsymbol{W}_{\boldsymbol{V}}$ \\
\hline Cubic capacity $D_{E}$ & - & 0.9181 & 0.8865 & 0.9040 & 0.8195 & -0.0404 & 0.7646 \\
Quantity of cylinders $N_{C}$ & 0.9181 & - & 0.9085 & 0.8425 & 0.7625 & -0.0812 & 0.6729 \\
Quantity of valves $N_{V}$ & 0.8865 & 0.9085 & - & 0.8396 & 0.7500 & -0.0953 & 0.6967 \\
Max. power $P_{M A X}$ & 0.9040 & 0.8425 & 0.8396 & - & 0.8367 & -0.2092 & 0.6999 \\
Max. torque $T_{M A X}$ & 0.8195 & 0.7625 & 0.7500 & 0.8367 & - & 0.2390 & 0.7984 \\
Compression rate $C_{R}$ & -0.0404 & -0.0812 & -0.0953 & -0.2092 & 0.2390 & - & 0.1653 \\
Kerb weight of vehicle $W_{V}$ & 0.7646 & 0.6729 & 0.6967 & 0.6999 & 0.7984 & 0.1653 & - \\
\hline
\end{tabular}

The values of the input and output variables, before being used for learning, testing and validation process of the neural network, were subjected to the normalization process, according to Formula (7). All normalized values of the quantitative variables are in the range $[0 ; 1]$. Each nominal value of all qualitative variables is assigned a corresponding neuron in the input layer, while the signal coming from such a neuron takes a binary value (0 or 1$)$ :

$$
x_{s}=\frac{x-x_{\min }}{x_{\max }-x_{\min }},
$$

where: $x_{s}$-value of standardized quantitative variable, $x$-value of a quantitative variable before normalization, $x_{\min }-$ minimum value of a quantitative variable and $x_{\text {max }}$-maximum value of the quantitative variable.

Figures 2 and 3 show the relationships between fuel consumption $\left(F C_{U}, F C_{H}, F C_{M}\right)$ and the quantity and quality parameters of a vehicle. The graphical visualisation of the input data illustrates the broad range of research carried out and the high multifacetedness of relations between the individual variables of the predictive model. The shapes of the plots are similar to each other within individual input variables. Depending on output variable, the respective shapes come across as being scaled accordingly. This indicates the possibility of developing one predictive model for three predicted variables. This model corresponds to the neural network, containing three neurons in the output layer. The visual effect of scaling the plots will be reflected in the appropriate assignment of weights of the synaptic connections between the neurons of the hidden layer and the output layer. 

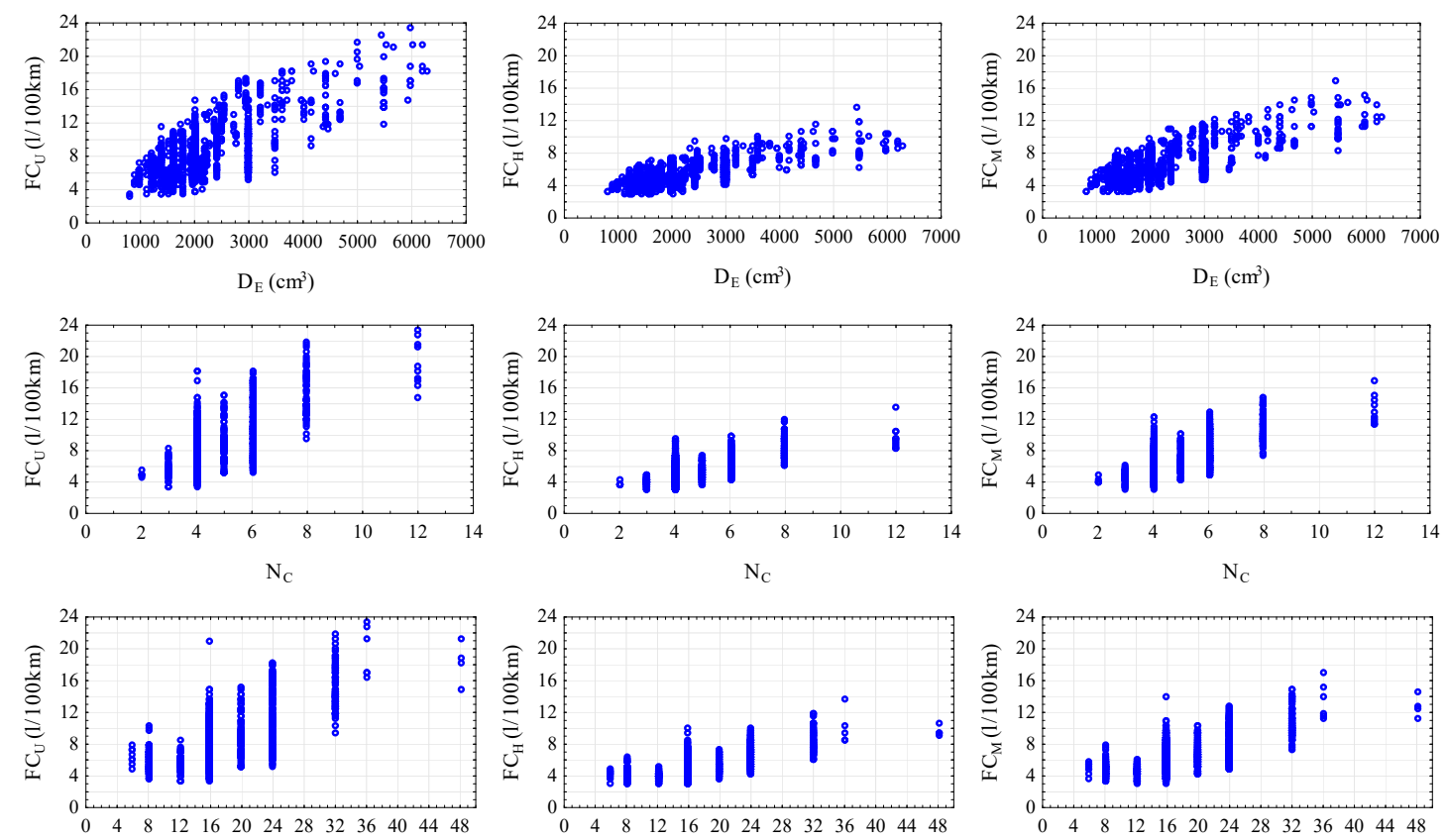

$\mathrm{N}_{\mathrm{V}}$

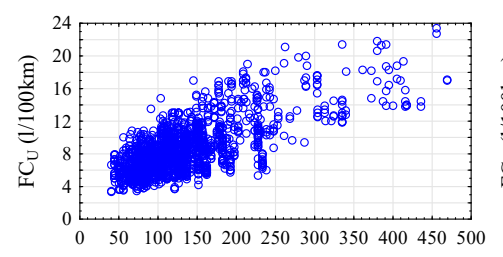

$\mathrm{N}_{\mathrm{V}}$

$\mathrm{N}_{\mathrm{V}}$
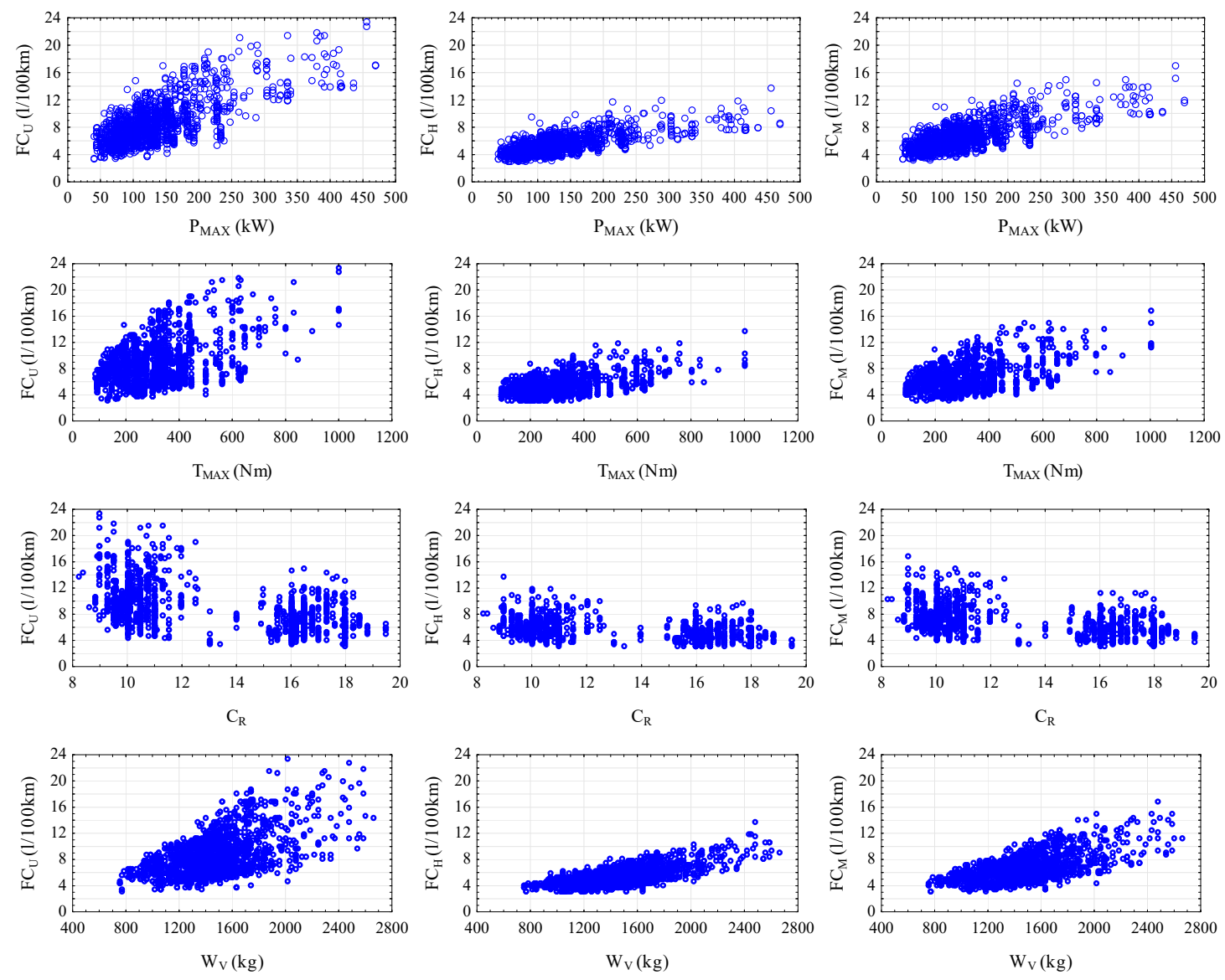

Figure 2. Fuel consumption depending on the quantitative input variables. 

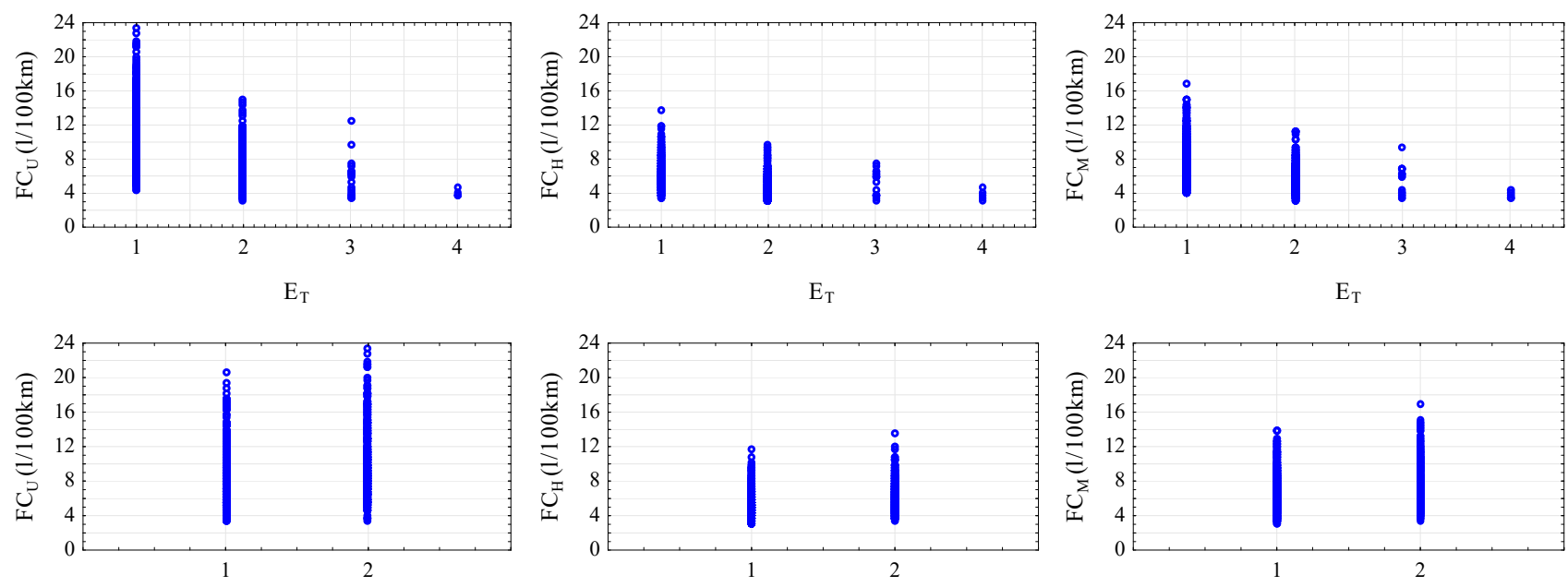

$\mathrm{F}_{\mathrm{I}}$

$\mathrm{F}_{\mathrm{I}}$
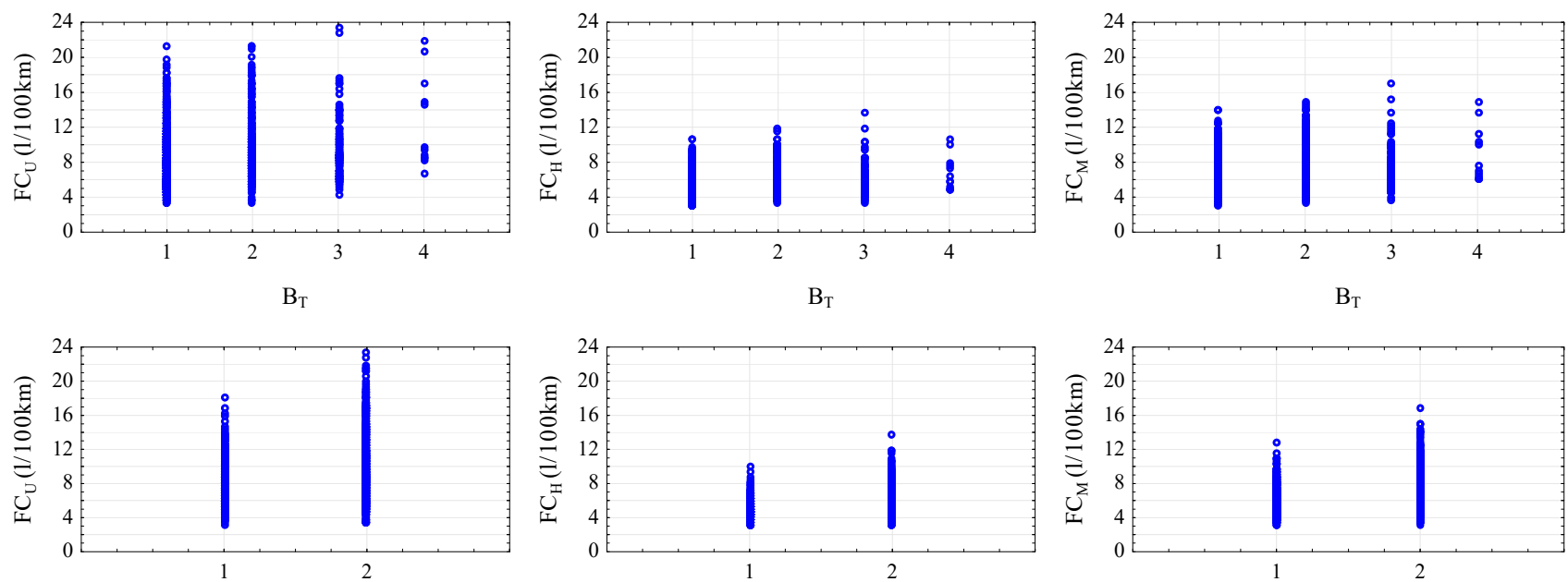

$\mathrm{T}_{\mathrm{G}}$

$\mathrm{T}_{\mathrm{G}}$

$\mathrm{T}_{\mathrm{G}}$
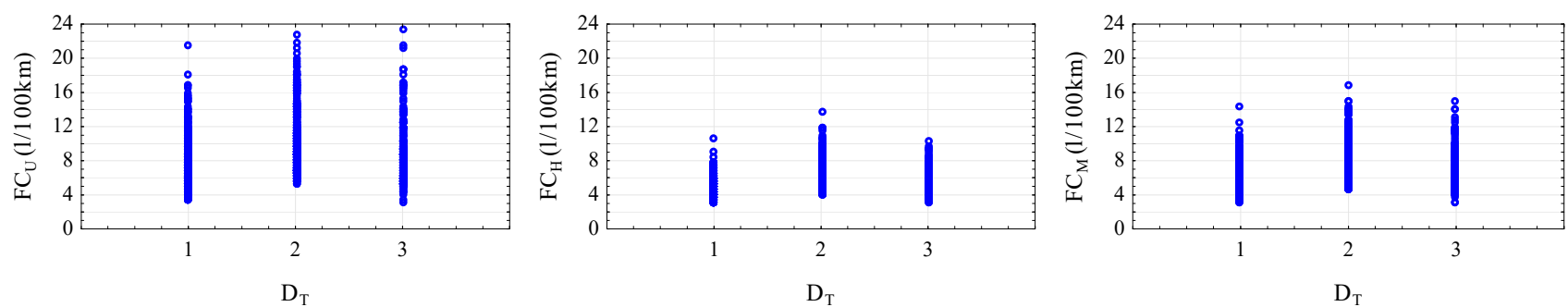

Figure 3. Fuel consumption depending on the qualitative input variables.

\section{Results}

To create the artificial neural network, Statistica 13 software was used, in which the proprietary database developed on basis of the technical parameters of passenger cars was analysed. The database was divided at random by the programme into three sets: training $(80 \%)$, testing $(10 \%)$ and validation $(10 \%)$. The neural network derives information from the data transmitted to it and on this basis, it conducts a learning process, i.e., a selection of the appropriate activation functions of the neurons and weights of the pathways between neurons. The use of Statistica software for modelling artificial neural networks accelerated and improved the process of calculation of the training algorithms. The exceptions are papers $[22,35,37,42]$, in which Matlab software was used to create the neural networks. 


\subsection{ANN Model with 12 Input Variables}

Upon the user issuing a command, the programme automatically generated 1000 artificial neural networks, of which it retained the ten best solutions. Their characteristics are presented in Table 5.

Table 5. List of the artificial neural network with 12 input variables.

\begin{tabular}{cccccccccc}
\hline No & $\begin{array}{c}\text { Network } \\
\text { Structure }\end{array}$ & $\begin{array}{c}\text { Accuracy } \\
\text { (Train.) }\end{array}$ & $\begin{array}{c}\text { Accuracy } \\
\text { (Test) }\end{array}$ & $\begin{array}{c}\text { Accuracy } \\
\text { (Val.) }\end{array}$ & $\begin{array}{c}\text { Error } \\
\text { (Train.) }\end{array}$ & $\begin{array}{c}\text { Error } \\
\text { (Test) }\end{array}$ & $\begin{array}{c}\text { Error } \\
\text { (Valid.) }\end{array}$ & Algorithm & Activation Functions \\
\hline 1 & MLP 22-10-3 & 0.9355 & 0.9512 & 0.9359 & 0.9105 & 0.8527 & 0.9431 & BFGS 79 & Tanh/Linear \\
2 & MLP 22-17-3 & 0.9371 & 0.9507 & 0.9382 & 0.8920 & 0.8617 & 0.9370 & BFGS 84 & Tanh/Linear \\
3 & MLP 22-21-3 & 0.9286 & 0.9503 & 0.9355 & 1.0156 & 0.8687 & 0.9410 & BFGS 47 & Tanh/Linear \\
4 & MLP 22-22-3 & 0.9317 & 0.9522 & 0.9321 & 0.9705 & 0.8497 & 1.0237 & BFGS 61 & Tanh/Linear \\
5 & MLP 22-10-3 & 0.9290 & 0.9518 & 0.9335 & 1.0052 & 0.8300 & 0.9921 & BFGS 46 & Sigmoidal/Linear \\
6 & MLP 22-25-3 & 0.9332 & 0.9508 & 0.9334 & 0.9496 & 0.8198 & 0.9558 & BFGS 47 & Tanh/Sigmoidal \\
7 & MLP 22-17-3 & 0.9328 & 0.9502 & 0.9330 & 0.9567 & 0.8454 & 0.9895 & BFGS 41 & Tanh/Sigmoidal \\
$\mathbf{8}$ & MLP 22-10-3 & $\mathbf{0 . 9 3 7 0}$ & $\mathbf{0 . 9 4 6 1}$ & $\mathbf{0 . 9 4 3 2}$ & $\mathbf{0 . 8 8 9 5}$ & $\mathbf{0 . 9 1 4 6}$ & $\mathbf{0 . 8 2 1 8}$ & BFGS 84 & Exponential/Sigmoidal \\
9 & MLP 22-15-3 & 0.9397 & 0.9481 & 0.9394 & 0.8639 & 0.8772 & 0.8909 & BFGS 79 & Exponential/Exponential \\
10 & MLP 22-15-3 & 0.9437 & 0.9467 & 0.9410 & 0.8088 & 0.9110 & 0.8869 & BFGS 110 & Exponential/Sigmoidal \\
\hline
\end{tabular}

All created artificial neural networks have an important common feature: an equal quantity of neurons in the input layer and in the output layer. This is conditioned by the quantity of the input and output variables. Each quantitative variable generates one neuron, while each qualitative variable generates as many neurons as the different values it takes. Among the ten networks retained in the programme, the one with the smallest number of errors in the validation set was selected. This is network No. 8 (MLP 22-10-3), comprising 10 neurons in the hidden layer. The network uses the BFGS learning algorithm and the SOS (sum of squares) error function. The learning, testing and validation errors presented in Table 5 correspond to half of the mean square error calculated from the values of unnormalized input variables for each set. The best selection of the weights of the synaptic pathway was achieved in 84th learning cycle network. The MLP 22-10-3 neural network learning diagram, showing changes in the value of half the mean square error for the normalized values of the variables in individual epochs (learning cycles), is presented in two scales in Figure 4. The activation functions are, respectively, for the hidden layerexponential function and for the output layer-unipolar sigmoid function. The weights of the synaptic pathways in the MLP 22-10-3 network are presented in Appendix A.
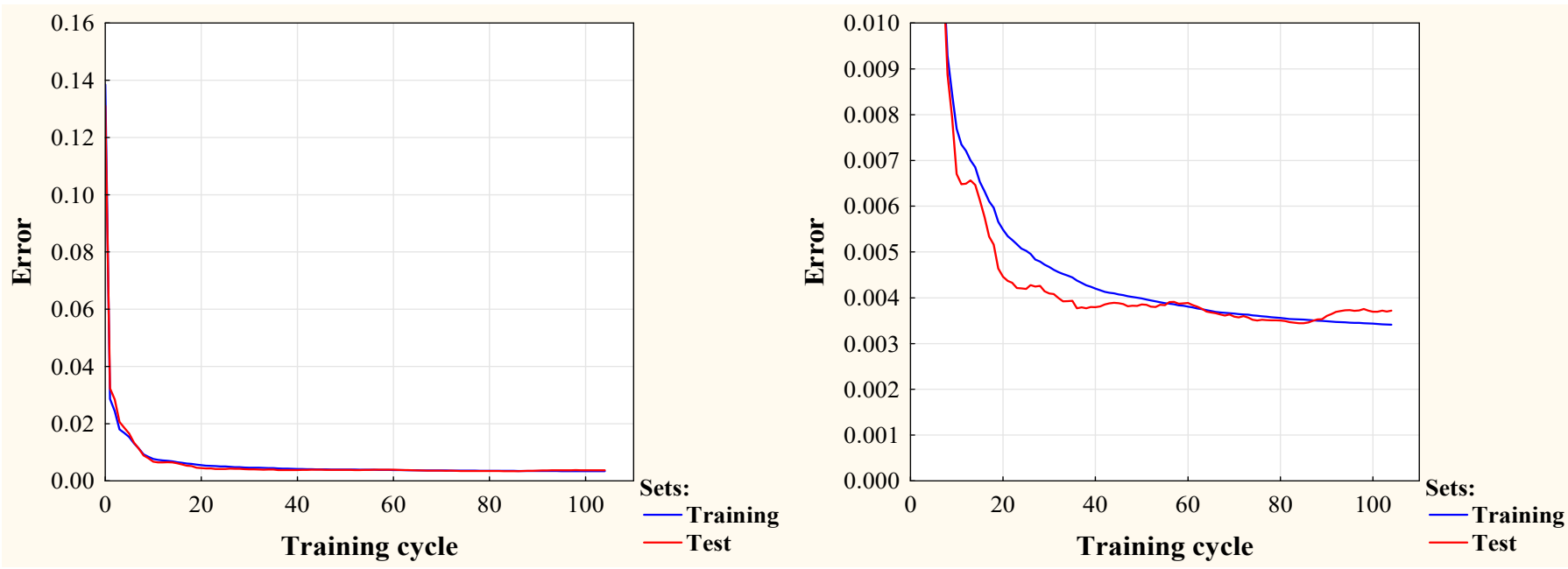

Figure 4. Learning plot of the MLP 22-10-3 artificial neural network. 
In Figure 5, a simplified model of the selected MLP 22-10-3 artificial neural network is presented, which has the lowest error value for the test set. The input layer (red) has 22 neurons, the hidden layer (blue) - 10 neurons, and the output layer (green) - 3 neurons. To each input neuron a quantitative input variable or one nominal value of a qualitative input variable is assigned. Each output neuron corresponds to one assigned output variable describing fuel consumption in a given environment. The synaptic pathways occur between the neurons from the input and the hidden layer, and between the hidden and the output neuron, by combining each neuron from the concerned layer with each neuron from the adjacent layer.

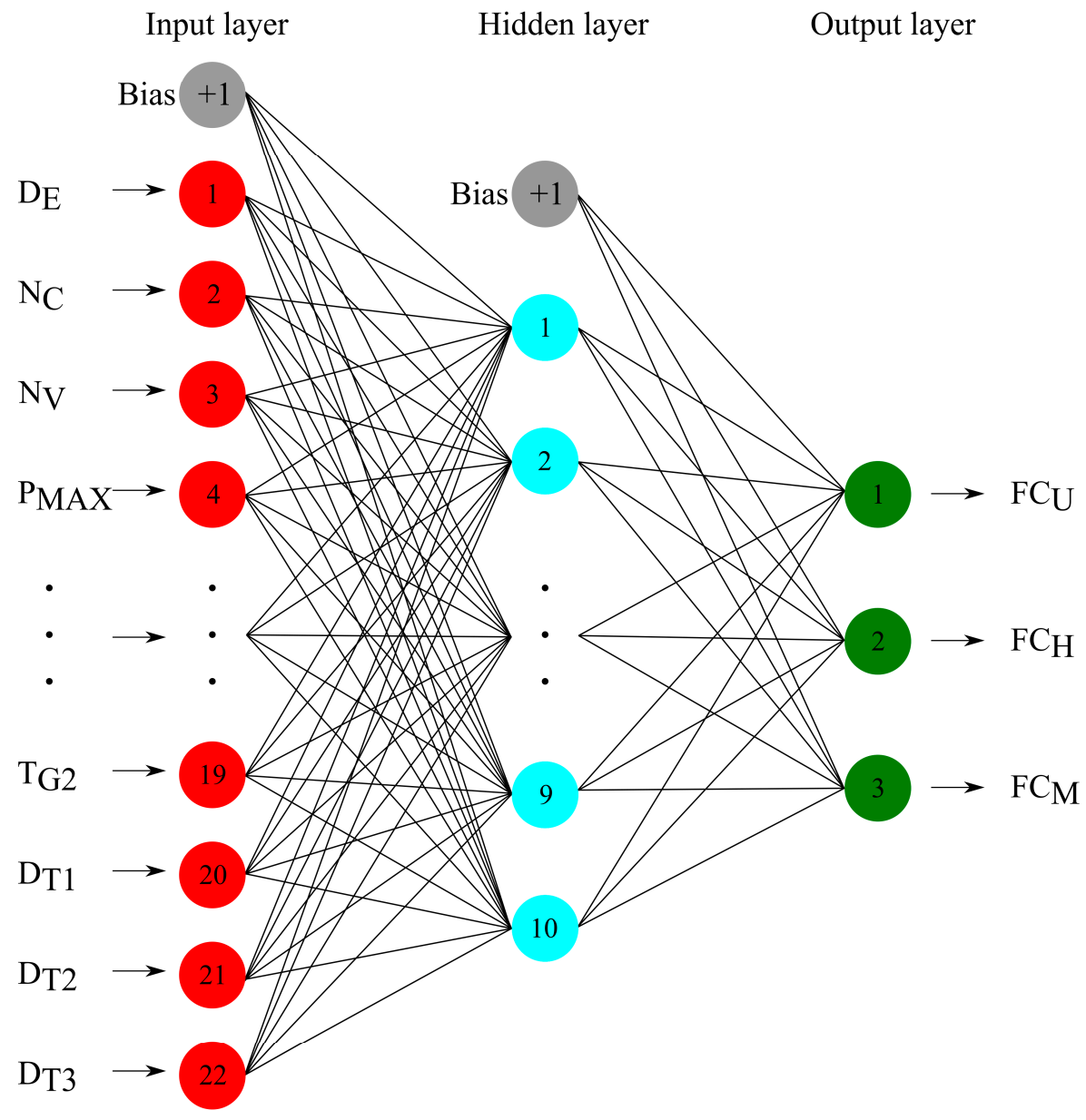

Figure 5. Simplified model of the MLP 22-10-3 artificial neural network.

The values of the correlation coefficients $r$ and the coefficient of determination $R^{2}$ for the selected neural network MLP 22-10-3 are shown in Table 6. For all variables in each sample, the value of correlation coefficient $r$ was above 0.93 , reaching a maximum value of 0.9499 for the $F C_{M}$ variable in the Test trial. The coefficient of determination $R^{2}$ for all variables reached values above 0.98 .

The plots of dispersion of real values and values of predicted variables $F C_{U}, F C_{H}$ and $F C_{M}$ divided by datasets are presented in Figure 6. Above each of the plots there are the linear regression formulas. The high values of the correlation coefficient $r$ and the coefficient of determination $R^{2}$ and a small quantity of outliers in the plots indicate a good matching of the model to the real data. 
Table 6. Correlation coefficients $r$ and coefficients of determination $R^{2}$ for the MLP 22-10-3 artificial neural network.

\begin{tabular}{cccccc}
\hline \multirow{2}{*}{ Correlation Coefficient } & \multirow{2}{*}{ Variable } & \multicolumn{3}{c}{ Set } \\
\cline { 3 - 6 } & & All & Training & Test & Validation \\
\hline \multirow{2}{*}{$r$} & $F C_{U}$ & 0.9381 & 0.9363 & 0.9450 & 0.9440 \\
& $F C_{H}$ & 0.9345 & 0.9331 & 0.9434 & 0.9369 \\
& $F C_{M}$ & 0.9432 & 0.9415 & 0.9499 & 0.9486 \\
\hline \multirow{2}{*}{$R^{2}$} & $F C_{U}$ & 0.9861 & 0.9862 & 0.9859 & 0.9879 \\
& $F C_{H}$ & 0.9925 & 0.9939 & 0.9922 & 0.9930 \\
& $F C_{M}$ & 0.9910 & 0.9915 & 0.9907 & 0.9922 \\
\hline
\end{tabular}
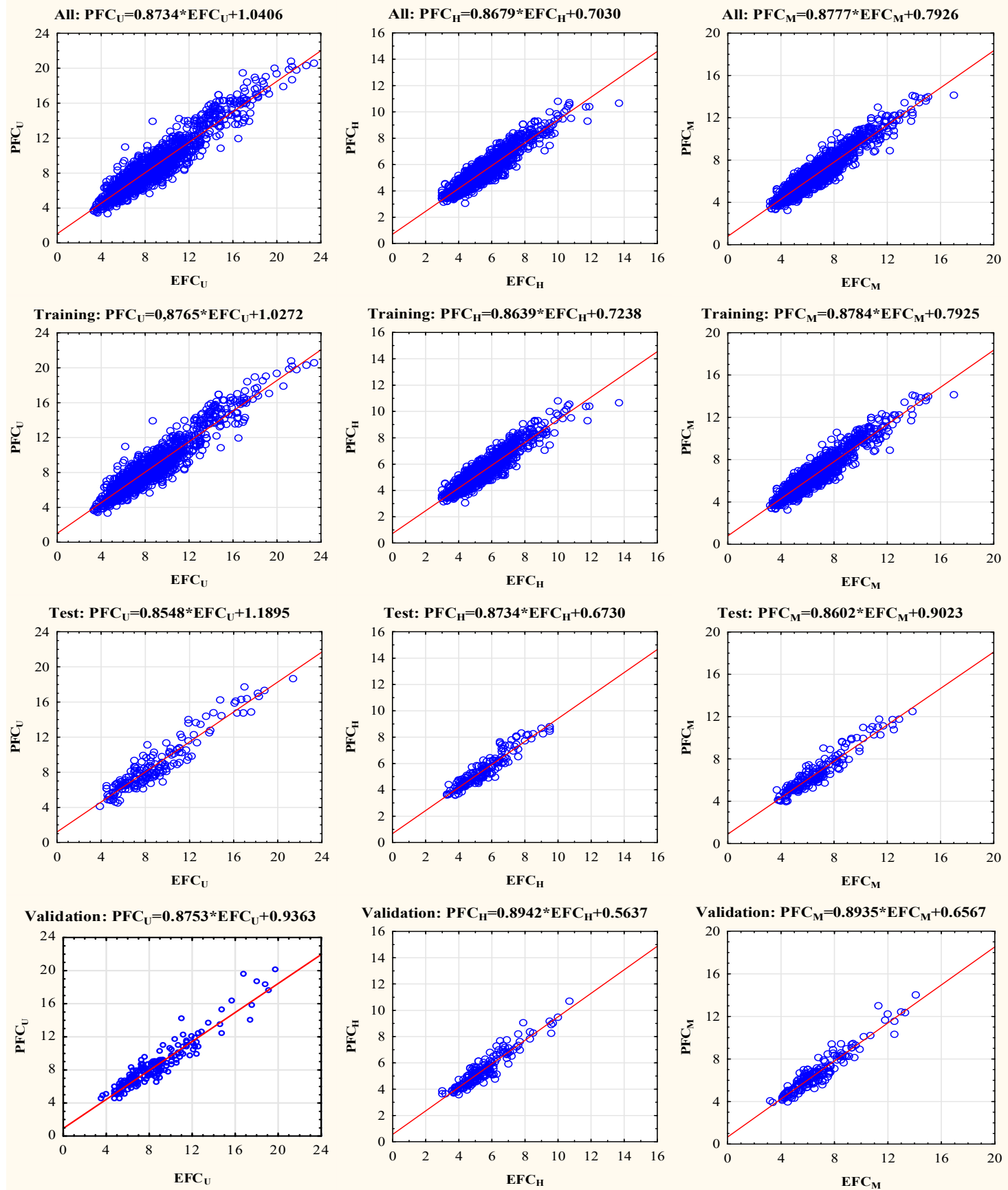

Figure 6. Regression plots of the MLP 22-10-3. 
For the purposes of determining the magnitude of impact of individual input variables on the accuracy of the predictive model, a global sensitivity analysis was conducted. The results of the analysis are presented in Table 7 . The sensitivity coefficient $W_{j}$ of the Gearbox $T_{G}$ variable is equal to exactly 1 , which means that this variable has no impact on the MSE error of the prediction.

Table 7. Global sensitivity analysis of the MLP 22-10-3 artificial neural network.

\begin{tabular}{ccccccccccccc}
\hline \multicolumn{11}{c}{ Input Variable } \\
\hline & $E_{T}$ & $F_{I}$ & $D_{E}$ & $P_{M A X}$ & $W_{V}$ & $B_{T}$ & $T_{M A X}$ & $N_{C}$ & $C_{R}$ & $D_{T}$ & $N_{V}$ & $T_{G}$ \\
\hline$W_{j}$ & 13.5900 & 4.0619 & 3.0441 & 2.7966 & 2.4305 & 1.9532 & 1.5222 & 1.3797 & 1.3096 & 1.2963 & 1.1049 & 1.0000 \\
\hline
\end{tabular}

\subsection{ANN Model with 11 Input Variables}

The next stage of the research is an attempt to optimise the artificial neural network. It is based on the results received in the sensitivity analysis of the input variables. Therefore, a hypothesis was put forward assuming that an elimination of the $T_{G}$ variable from the set of the input variables will not reduce the prediction accuracy by the neural network. Using Statistica software, the process of creating the artificial neural networks was conducted, including 11 input variables and 3 output variables. The quantity of neurons in the input layer was decreased, while at the same time maintaining the quantity of neurons in the hidden layer and the activation functions of the individual layers such as in the MLP 22-10-3 network. In Table 8 the results of the created ten neural networks featuring the MLP 20-10-3 structure are presented.

Table 8. List of the artificial neural network with 11 input variables.

\begin{tabular}{cccccccccc}
\hline No & $\begin{array}{c}\text { Network } \\
\text { Structure }\end{array}$ & $\begin{array}{c}\text { Accuracy } \\
\text { (Train.) }\end{array}$ & $\begin{array}{c}\text { Accuracy } \\
\text { (Test) }\end{array}$ & $\begin{array}{c}\text { Accuracy } \\
\text { (Val.) }\end{array}$ & $\begin{array}{c}\text { Error } \\
\text { (Train.) }\end{array}$ & $\begin{array}{c}\text { Error } \\
\text { (Test) }\end{array}$ & $\begin{array}{c}\text { Error } \\
\text { (Valid.) }\end{array}$ & Algorithm & Activation Functions \\
\hline 1 & MLP 20-10-3 & 0.9474 & 0.9519 & 0.9229 & 0.7486 & 0.8446 & 1.0351 & BFGS 413 & Exponential/Sigmoidal \\
2 & MLP 20-10-3 & 0.9439 & 0.9462 & 0.9343 & 0.8061 & 0.9071 & 0.9479 & BFGS 151 & Exponential/Sigmoidal \\
Exponential/Sigmoidal \\
$\mathbf{3}$ & MLP 20-10-3 & $\mathbf{0 . 9 3 3 5}$ & $\mathbf{0 . 9 4 4 1}$ & $\mathbf{0 . 9 4 1 6}$ & $\mathbf{0 . 9 3 8 9}$ & $\mathbf{0 . 9 5 7 2}$ & $\mathbf{0 . 8 3 4 3}$ & BFGS 77 & Exponential/Sigmoidal \\
4 & MLP 20-10-3 & 0.9360 & 0.9438 & 0.9382 & 0.9007 & 0.9896 & 0.9210 & BFGS 99 & Expon \\
5 & MLP 20-10-3 & 0.9422 & 0.9457 & 0.9196 & 0.8284 & 0.9414 & 1.0715 & BFGS 187 & Exponential/Sigmoidal \\
6 & MLP 20-10-3 & 0.9425 & 0.9445 & 0.9347 & 0.8157 & 0.9350 & 0.9668 & BFGS 178 & Exponential/Sigmoidal \\
7 & MLP 20-10-3 & 0.9332 & 0.9450 & 0.9338 & 0.9436 & 0.9386 & 0.9031 & BFGS 74 & Exponential/Sigmoidal \\
8 & MLP 20-10-3 & 0.9438 & 0.9482 & 0.9243 & 0.8020 & 0.9066 & 1.0611 & BFGS 229 & Exponential/Sigmoidal \\
9 & MLP 20-10-3 & 0.9445 & 0.9492 & 0.9199 & 0.7908 & 0.8676 & 1.1337 & BFGS 265 & Exponential/Sigmoidal \\
10 & MLP 20-10-3 & 0.9361 & 0.9459 & 0.9373 & 0.9077 & 0.9304 & 0.8999 & BFGS 93 & Exponential/Sigmoidal \\
\hline
\end{tabular}

The network with the lowest error on the validation set, assuming the value of 0.8343 , is network No. 3. It uses the BFGS learning algorithm, which found the best selection of the synaptic pathway weights in 77 learning cycles. The MLP 20-10-3 neural network learning diagram, showing changes in the value of half of the mean square error for the normalized values of the variables in individual epochs (learning cycles), is presented in two scales in Figure 7 . The errors made by the networks with 11 input variables take similar values to those made by the networks with 12 input variables. The weights of the synaptic pathways in the MLP 20-10-3 network are presented in Appendix B.

A simplified model of the MLP 20-10-3 network is shown in Figure 8. The selection of colour markings of the layers corresponds to the model shown in Figure 5, similarly to the manner of the synaptic pathways between the neurons of the adjacent layers. 

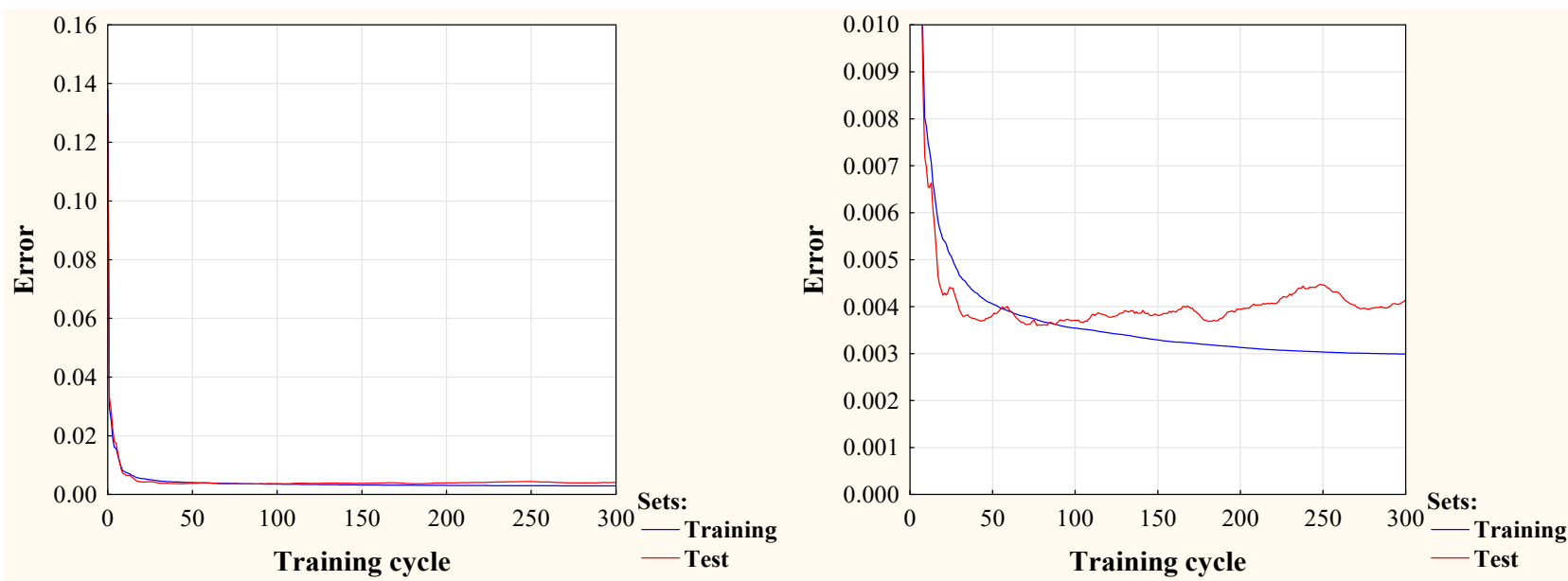

Figure 7. Learning plot of the MLP 20-10-3 networks.

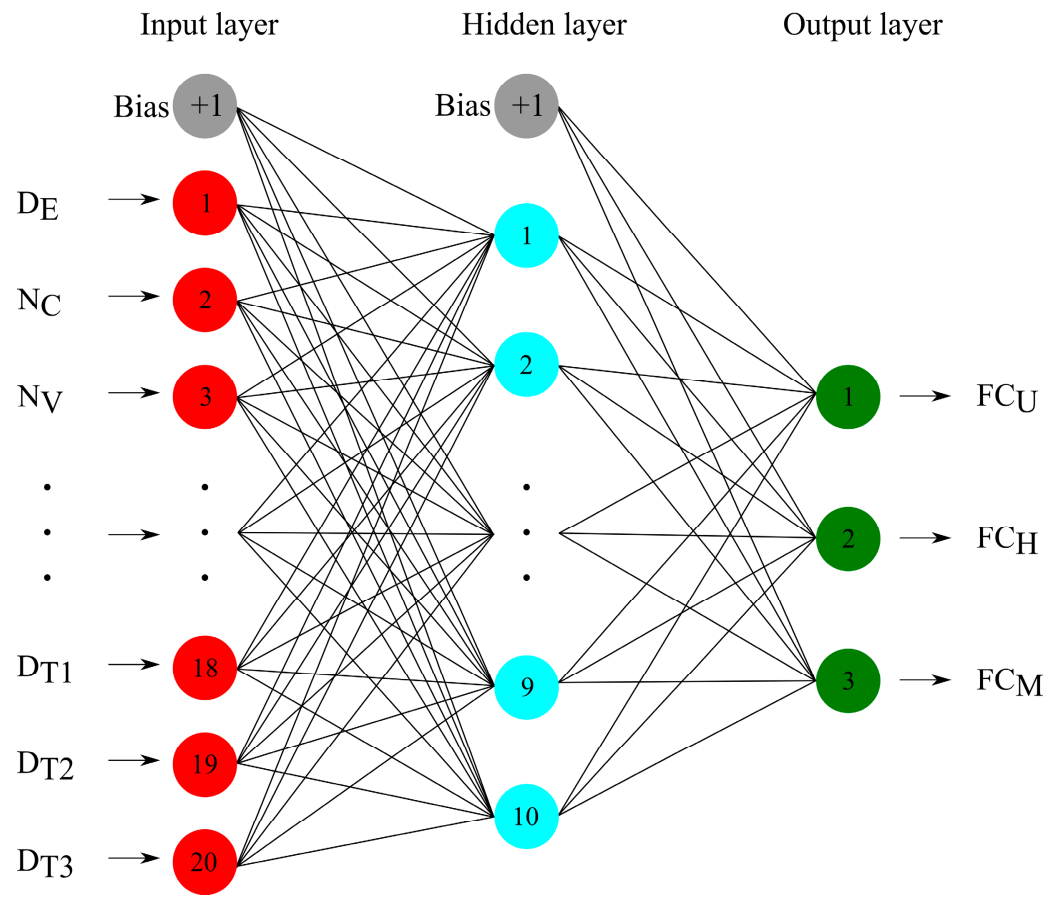

Figure 8. Simplified model of the MLP 20-10-3 artificial neural network.

The Pearson correlation coefficients $r$ and the coefficients of determination $R^{2}$ divided into the output variables and database sets are presented in Table 9. The highest value of the correlation coefficient $\mathrm{r}$ is achieved by the $F C_{M}$ variable for the Test set and the lowest value - the $F C_{H}$ variable for the Training set. All values of the $r$ coefficient are in the range 0.93-0.95, whereas the $R^{2}$ coefficient, similarly to in the MLP 22-10-3 model, assumed values above 0.98 , which is a result similar to the results achieved within the previous studies by other authors $[8,32,35,42]$. Nevertheless, it should be mentioned that the papers published so far are based on a significantly narrower group of vehicles featuring similar technical parameters, which facilitates the adjustment of the predictive model to the experimental values.

In Figure 9 the plots of the dispersion of the experimental values (declared by the manufacturers) and the values predicted by the MLP 20-10-3 artificial neural network for the variables $F C_{U}, F C_{H}$ and $F C_{M}$, respectively, are shown. Above each of the plots the linear regression formulas are described. The values of the correlation coefficient $r$ and the coefficient of determination $R^{2}$ and a small quantity of outliers in the plots indicate a good matching of the model to the real data. 
Table 9. Pearson correlation coefficients $r$ and the coefficients of determination $R^{2}$ for the MLP 20-10-3 neural network.

\begin{tabular}{cccccc}
\hline \multirow{2}{*}{ Correlation Coefficient } & & \multicolumn{3}{c}{ Set } \\
\cline { 3 - 6 } & Variable & All & Training & Test & Validation \\
\cline { 3 - 6 } & $F C_{U}$ & 0.9350 & 0.9327 & 0.9430 & 0.9433 \\
& $F C_{H}$ & 0.9318 & 0.9300 & 0.9417 & 0.9358 \\
& $F C_{M}$ & 0.9396 & 0.9377 & 0.9477 & 0.9457 \\
\hline \multirow{2}{*}{$R^{2}$} & $F C_{U}$ & 0.9855 & 0.9856 & 0.9851 & 0.9879 \\
& $F C_{H}$ & 0.9922 & 0.9937 & 0.9919 & 0.9928 \\
& $F C_{M}$ & 0.9904 & 0.9910 & 0.9901 & 0.9917 \\
\hline
\end{tabular}
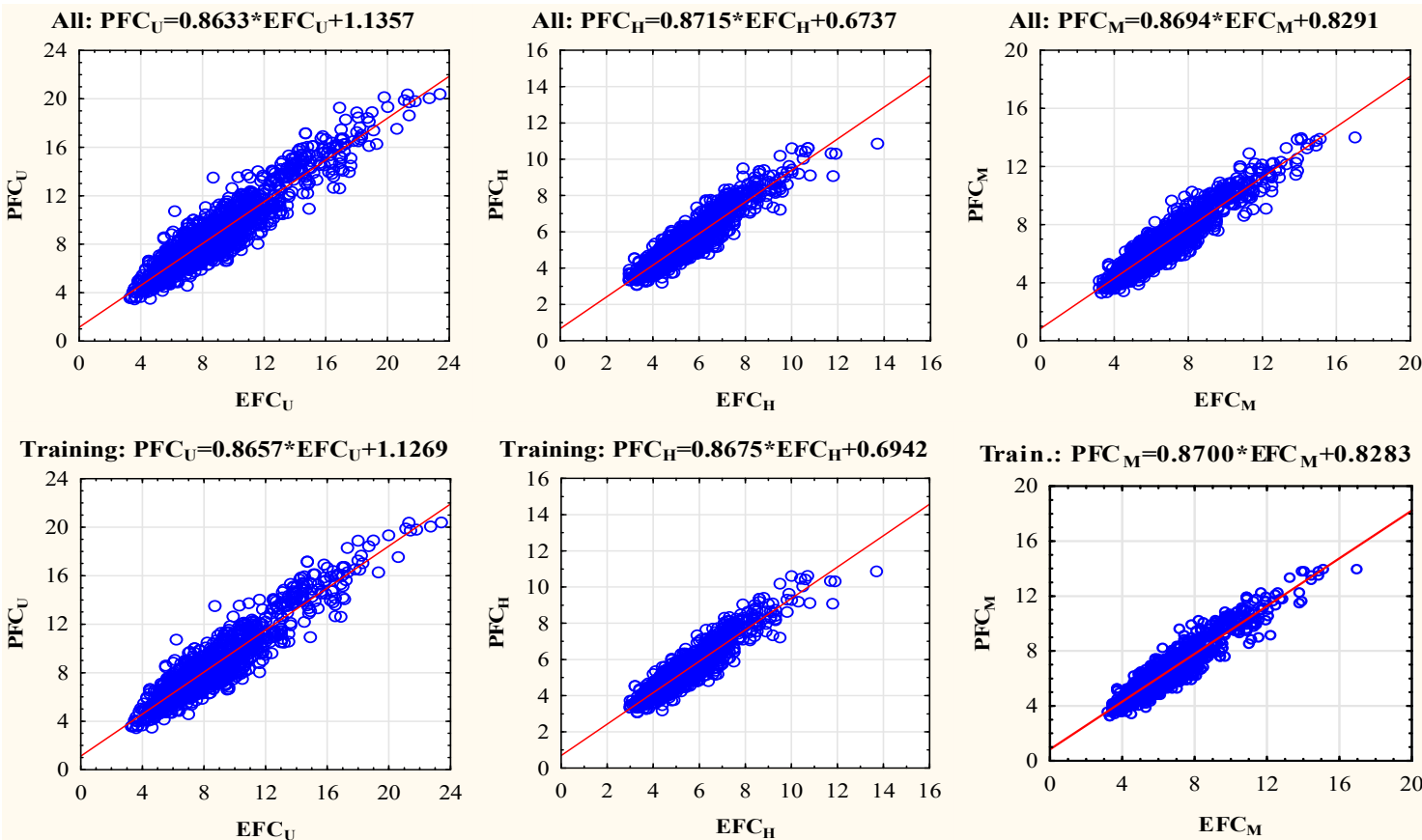

Training: $\mathrm{PFC}_{\mathrm{H}}=0.8675 * \mathrm{EFC}_{\mathrm{H}}+\mathbf{0 . 6 9 4 2}$

Train.: PFC $_{M}=0.8700 * \mathrm{EFC}_{M^{+0.8283}}$
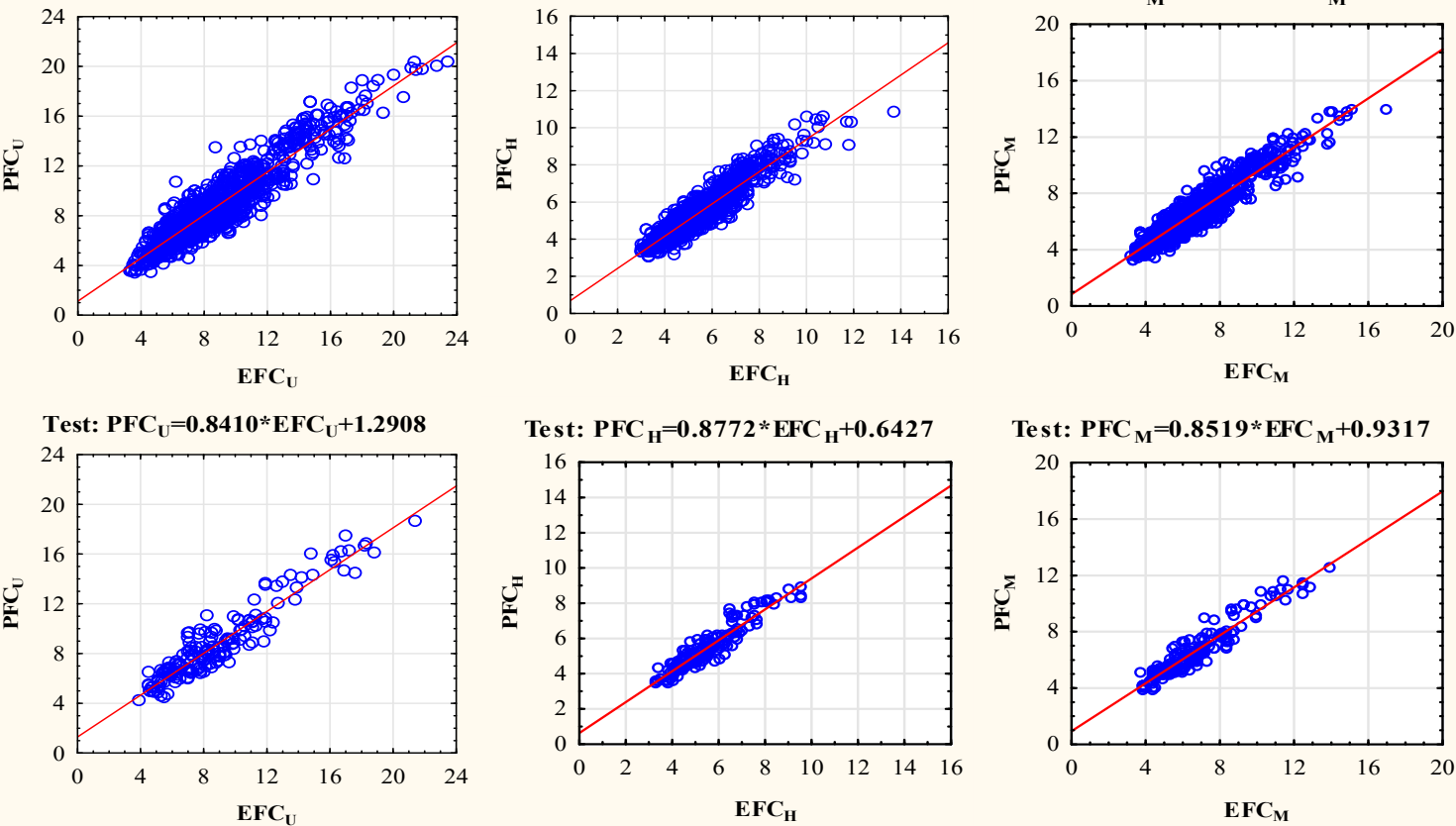

Test: PFC $_{\mathbf{H}}=0.8772 * \mathrm{EFC}_{\mathbf{H}}+\mathbf{0 . 6 4 2 7}$

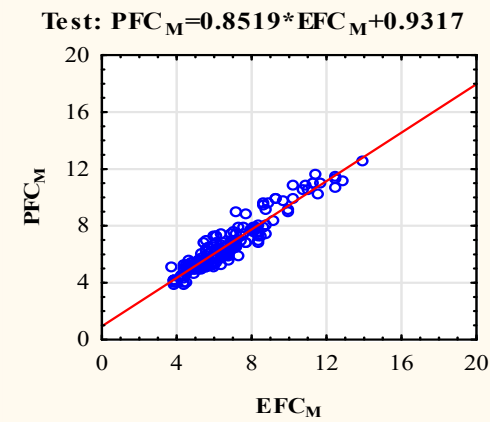

Valid.: PFC $_{U}=0.8750 * \mathrm{EFC}_{U}+0.9848$
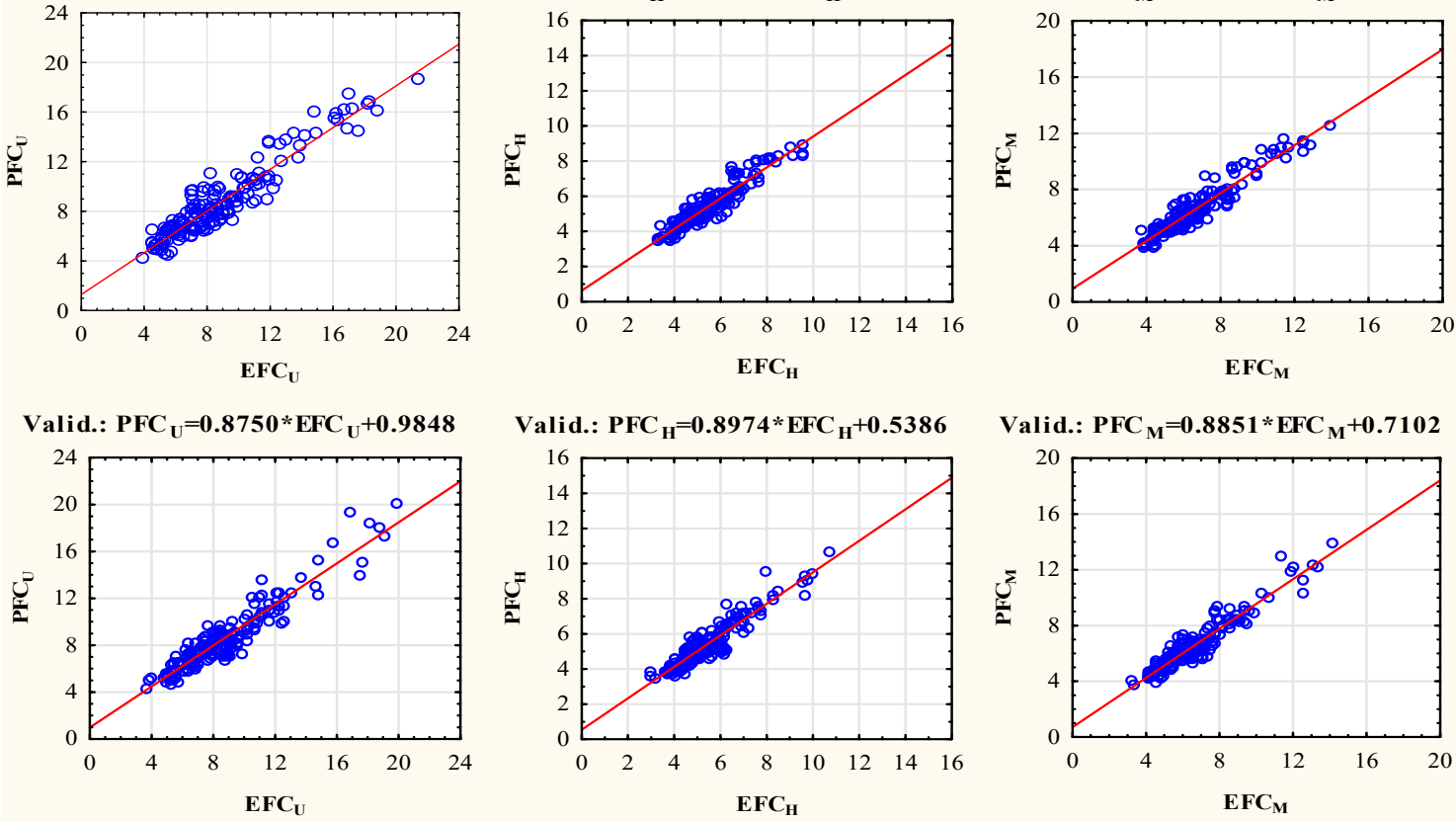

Figure 9. Regression plots of the MLP 20-10-3 artificial neural network. 
The global sensitivity analysis for the MLP 20-10-3 network, presented in Table 10, indicates the influence of the values of the individual input variables on the accuracy of the predictive model. The neural network has the highest sensitivity to the Type of charge $B_{T}$ variables and the lowest sensitivity to the Quantity of valves $N_{V}$ variables. However, no value is equal to or less than 1 . Therefore, no further attempts were made to decrease the quantity of input variables for the neural network.

Table 10. Global sensitivity analysis of the MLP 20-10-3 artificial neural network.

\begin{tabular}{|c|c|c|c|c|c|c|c|c|c|c|c|}
\hline \multicolumn{12}{|c|}{ Input Variable } \\
\hline$W_{j}$ & $\begin{array}{c}E_{T} \\
16.0194\end{array}$ & $\begin{array}{c}F_{I} \\
3.2997\end{array}$ & $\begin{array}{c}D_{E} \\
3.2528\end{array}$ & $\begin{array}{c}B_{T} \\
2.4795\end{array}$ & $\begin{array}{c}W_{V} \\
2.2873\end{array}$ & $\begin{array}{l}P_{\text {MAX }} \\
1.8756\end{array}$ & $\begin{array}{c}D_{T} \\
1.3758\end{array}$ & $\begin{array}{l}T_{M A X} \\
1.3124\end{array}$ & $\begin{array}{c}N_{C} \\
1.2954\end{array}$ & $\begin{array}{c}C_{R} \\
1.2855\end{array}$ & $\begin{array}{c}N_{V} \\
1.0993\end{array}$ \\
\hline
\end{tabular}

\section{Discussion}

On the basis of Equations (4)-(6), the ex post prediction errors were calculated for all vehicles used in the database. The results of the calculations are presented in Table 11. The $R M S E$ values were in the range 0.40-1.15. The MSE achieved low values for the $F C_{H}$ and $F C_{M}$ variables, being equal in the validation set to 0.2249 and 0.3799 , respectively, in case of the MLP 22-10-3 network, and 0.2292 and 0.4010 in case of the MLP 20-10-3 network, which is a better result than the one achieved in other published studies bringing up the similar problematics [8], whereas the $M S E$ for the $F C_{U}$ variable slightly exceeded a value of 1.

Table 11. Prediction errors of the ANNs.

\begin{tabular}{|c|c|c|c|c|c|}
\hline \multirow{2}{*}{ Neural Network } & \multirow{2}{*}{ Variable } & \multirow{2}{*}{ Set } & \multicolumn{3}{|c|}{ Prediction Error } \\
\hline & & & MSE & RMSE & MAPE (\%) \\
\hline \multirow{12}{*}{ MLP 22-10-3 } & \multirow{4}{*}{$F C_{U}$} & All & 1.1232 & 1.0598 & 10.32 \\
\hline & & Training & 1.1215 & 1.0590 & 10.36 \\
\hline & & Test & 1.2216 & 1.1053 & 10.88 \\
\hline & & Validation & 1.0387 & 1.0192 & 8.39 \\
\hline & \multirow{4}{*}{$F C_{H}$} & All & 0.2307 & 0.4803 & 6.96 \\
\hline & & Training & 0.2362 & 0.4860 & 6.41 \\
\hline & & Test & 0.1920 & 0.4382 & 7.05 \\
\hline & & Validation & 0.2249 & 0.4742 & 5.35 \\
\hline & \multirow{4}{*}{$F C_{M}$} & All & 0.4166 & 0.6454 & 7.99 \\
\hline & & Training & 0.4213 & 0.6491 & 8.01 \\
\hline & & Test & 0.4157 & 0.6447 & 8.07 \\
\hline & & Validation & 0.3799 & 0.6164 & 5.06 \\
\hline \multirow{12}{*}{ MLP 20-10-3 } & \multirow{4}{*}{$F C_{U}$} & All & 1.1777 & 1.0852 & 10.57 \\
\hline & & Training & 1.1824 & 1.0874 & 10.64 \\
\hline & & Test & 1.2799 & 1.1313 & 11.13 \\
\hline & & Validation & 1.0383 & 1.0190 & 9.51 \\
\hline & \multirow{4}{*}{$F C_{H}$} & All & 0.2404 & 0.4903 & 7.07 \\
\hline & & Training & 0.2471 & 0.4971 & 6.50 \\
\hline & & Test & 0.1978 & 0.4447 & 7.18 \\
\hline & & Validation & 0.2292 & 0.4788 & 6.80 \\
\hline & \multirow{4}{*}{$F C_{M}$} & All & 0.4425 & 0.6652 & 8.16 \\
\hline & & Training & 0.4484 & 0.6696 & 8.24 \\
\hline & & Test & 0.4368 & 0.6609 & 8.16 \\
\hline & & Validation & 0.4010 & 0.6332 & 7.56 \\
\hline
\end{tabular}

In the literature [28], the level of acceptability of the prediction based on the MAPE is $10 \%$. In the conducted studies this level for the predicted values of the $F C_{U}, F C_{H}$ and $F C_{M}$ values is in the range of $5-11 \%$ for the MLP 22-10-3 network and in the range $6.5-11.5 \%$ for the MLP 20-10-3 network. However, for the validation set of all variables in both neural 
networks, the MAPE failed to exceed the acceptable value of $10 \%$. The lowest value of $5.06 \%$ was recorded for the $F C_{M}$ variable in the validation set of the MLP 22-10-3 network. For the accepted level of prediction acceptability, the prediction models developed can be determined as sufficiently accurate.

The value ranges of the predicting error measures confirm the appropriate selection of the explanatory variables used in the process of creating the predictive models based on the artificial neural networks. It should be understood that the technical parameters of motor vehicles that have an impact on the fuel consumption were properly determined. The sensitivity analysis of the predictive models indicated the influence of the individual variables on the accuracy of the prediction. An attempt to simplify the predictive model by rejecting the variable $T_{G}$ with a sensitivity coefficient $W_{j}$ equal to 1 resulted in a minimal difference in the accuracy between the model with 12 variables and the model with 11 input variables. In both models, the $E_{T}$ variable, which corresponds to the engine type, had the greatest impact on fuel consumption, due to the type of fuel used to operate it and the hybridisation aspect of the drive. Furthermore, there were the $F_{I}$ and $D_{E}$ variables, corresponding to the fuel injection method and engine displacement. Their significance in the predictive model is reflected in the development trends of the modern internal combustion engines. Most manufacturers in eth automotive industry are departing from the use of indirect injection engines towards direct injection in order to minimise fuel consumption and further reduce engine capacity (downsizing). A predicting tool, such as the artificial neural networks created, makes it possible to estimate fuel consumption on the basis of the assumptions made and the values of the individual variables for motor vehicles at the design stage.

\section{Conclusions}

This publication brings up the research problem of the prediction of the fuel consumption of motor vehicles equipped with internal combustion engines. An attempt was made to develop a prediction model capable of mapping the impact of the individual technical parameters of the vehicle on fuel consumption under different conditions of use. The literature review presented in the introduction indicates the topicality of the undertaken research subject. The objective of the research was to use artificial neural networks for the prediction of fuel consumption on the basis of the selected technical parameters and the design solutions of passenger cars. The research's subject was the results related to fuel consumption obtained during the international tests, according to the declarations of the manufacturers from the automotive industry. Passenger cars with different technical parameters, manufactured in the years 2010-2020, were used as the basis for creating the database used for training the artificial neural networks.

For the purposes of carrying out the research on the possibility of using artificial neural networks in the development of a predictive model of the fuel consumption of the motor vehicles, Statistica computer software was used, supporting the analysis of the statistical data. The created MLP 22-10-3 network was characterised by a high quality of training, testing and validation in the range 0.93-0.95. Furthermore, upon conducting a global sensitivity analysis, an attempt was made to optimise the neural network by eliminating one of the variables. The effect of the optimisation was to create a reduced MLP 20-10-3 artificial neural network characterised by levels of the quality of learning, test and validation similar to those of the MLP 22-10-3 ANN. Analysing the values of the correlation and determination coefficients between the experimental and predicted output variables and comparing them to the results obtained from research published by other authors, a high capability of the created artificial neural network to predict fuel consumption was determined.

Additionally, an analysis of the ex post predicting errors was carried out and used to compare the predicted values with real ones. The values of the MSE, RMSE and MAPE measures indicate the acceptable accuracy of the predictions made with the use of the predictive models: MLP 22-10-3 and MLP 20-10-3. To sum up, the use of the artificial 
intelligence allows us to estimate fuel consumption of passenger cars driven in different operating environments (urban, extraurban, mixed cycle) with high accuracy. At the same time, the high accuracy of the prediction indicates a proper determination of the technical parameters used as input variables in the predictive model.

The effectiveness of using artificial neural networks to predict the fuel consumption of a passenger car powered by internal combustion engine, already at the stage of its design on the basis of the technical parameters specified in the assumptions for the design is confirmed in this publication. It is a multi-faceted issue, manifested by the tendency of the automotive market to minimise fuel consumption in relation to the reduction of emissions of harmful chemical compounds into the environment. Further research should focus on improving the accuracy of the predictive models by making them more detailed and updating the database on a successive basis.

Author Contributions: Conceptualization, M.O. and J.Z.; methodology, M.O.; software, M.O.; validation, M.O. and J.Z.; formal analysis, M.O. and J.Z.; investigation, M.O. and J.S.-R.; resources, M.O.; data curation, M.O. and J.S.-R.; writing—original draft preparation, M.O.; writing-review and editing, M.O. and J.M.; visualization, M.O. and J.M.; supervision, J.Z.; project administration, J.M. and J.Z.; funding acquisition, J.M. All authors have read and agreed to the published version of the manuscript.

Funding: This research received no external funding.

Institutional Review Board Statement: Not applicable.

Informed Consent Statement: Not applicable.

Data Availability Statement: Not applicable.

Acknowledgments: This work was supported by Military University of Technology (project No. 878/WAT/2021). This support is gratefully acknowledged.

Conflicts of Interest: The authors declare no conflict of interest.

\section{Appendix A}

Weights of the synaptic pathways in the MLP 22-10-3 artificial neural network are presented in Tables A1 and A2.

Table A1. Weights between the input layer and hidden layer in the MLP 22-10-3 artificial neural network.

\begin{tabular}{|c|c|c|c|c|c|c|c|c|c|c|}
\hline \multirow{2}{*}{ Input Layer } & \multicolumn{10}{|c|}{ Hidden Layer } \\
\hline & 1 & 2 & 3 & 4 & 5 & 6 & 7 & 8 & 9 & 10 \\
\hline $1\left(D_{E}\right)$ & -1.6702 & -0.4328 & -0.7698 & 0.8842 & -1.3829 & -0.9280 & -0.6757 & -1.7382 & -0.6358 & -1.3018 \\
\hline $2\left(N_{C}\right)$ & -0.2134 & -0.2676 & -0.5045 & -0.7850 & -0.3062 & -0.8504 & 0.1644 & -0.6858 & -0.2788 & -0.0615 \\
\hline $3\left(N_{V}\right)$ & 0.5032 & 0.8776 & 0.4737 & 0.3170 & -0.7939 & 0.3828 & -0.8991 & 0.1832 & 0.1462 & 1.1559 \\
\hline $4\left(P_{M A X}\right)$ & -0.5863 & 0.1890 & 0.6193 & -1.6520 & -1.0632 & -2.2077 & -0.7404 & 0.8146 & -0.4640 & -0.3713 \\
\hline $5\left(T_{M A X}\right)$ & -0.0449 & 0.7842 & 0.2105 & 1.1824 & -0.9961 & 0.4626 & -0.1905 & 0.2780 & 0.6646 & 0.1408 \\
\hline $6\left(C_{R}\right)$ & -0.0791 & 0.0734 & 0.0366 & 0.3923 & 1.0082 & 2.2354 & 0.6899 & -0.1457 & 0.8236 & 0.4095 \\
\hline $7\left(W_{V}\right)$ & -0.1617 & -1.7266 & -0.6313 & -0.9371 & -0.6737 & -0.0869 & -0.1681 & -0.3257 & -0.0566 & -0.9544 \\
\hline $8\left(E_{T 1}\right)$ & -0.6947 & -0.0671 & -0.2853 & 0.9236 & -0.1842 & -0.0345 & -0.2660 & 0.2771 & -0.3976 & -0.6242 \\
\hline $9\left(E_{T 2}\right)$ & -0.6880 & -0.0323 & -0.1665 & 0.3564 & 0.2925 & -0.0290 & 0.4719 & -0.8035 & -0.4205 & -0.0219 \\
\hline $10\left(E_{T 3}\right)$ & 0.6815 & -0.1030 & 0.4876 & -1.5242 & 0.3250 & 0.2675 & -0.2736 & 0.3837 & 0.4258 & 0.3578 \\
\hline $11\left(E_{T 4}\right)$ & 0.5295 & 0.4399 & 0.2030 & -0.0720 & 0.2472 & 0.1064 & 0.3583 & 0.3559 & 0.2763 & 0.6396 \\
\hline $12\left(F_{I 1}\right)$ & -0.0227 & 0.2997 & 0.0685 & -0.8359 & 0.6512 & -0.1770 & 0.4561 & 1.1345 & -0.7756 & -0.1540 \\
\hline $13\left(F_{I 2}\right)$ & -0.1239 & -0.0892 & 0.1578 & 0.4585 & 0.0713 & 0.4177 & -0.1588 & -0.8407 & 0.6401 & 0.4933 \\
\hline $14\left(B_{T 1}\right)$ & -0.2002 & 0.1789 & 0.8938 & -0.4311 & -0.5010 & -0.4624 & -1.0636 & 0.3441 & -0.1712 & 0.0991 \\
\hline $15\left(B_{T 2}\right)$ & -0.0327 & 0.0590 & -0.3720 & 0.1708 & 0.9242 & 0.5391 & 0.2677 & -0.0638 & 0.0356 & 0.0960 \\
\hline $16\left(B_{T 3}\right)$ & 0.2697 & -0.1014 & -0.3337 & 0.1720 & -0.0261 & 0.7786 & 0.5561 & -0.0178 & 0.1086 & 0.3105 \\
\hline $17\left(B_{T 4}\right)$ & -0.1344 & 0.1468 & 0.0944 & -0.2452 & 0.3221 & -0.5298 & 0.4897 & -0.0211 & -0.0674 & -0.1185 \\
\hline $18\left(T_{G 1}\right)$ & 0.5821 & 0.1392 & -0.1230 & -0.3436 & 0.2794 & 0.1048 & -0.0507 & 0.1859 & -0.0826 & 0.4532 \\
\hline $19\left(T_{G 2}\right)$ & -0.7316 & 0.1256 & 0.4036 & -0.0241 & 0.4630 & 0.2031 & 0.3125 & 0.0607 & -0.0714 & -0.1088 \\
\hline $20\left(D_{T 1}\right)$ & 0.2578 & 0.0524 & 0.0842 & -0.1878 & 0.2959 & 0.0029 & -0.0104 & 0.1082 & -0.1622 & 0.1625 \\
\hline $21\left(D_{T 2}\right)$ & 0.1273 & 0.0253 & 0.2565 & -0.0907 & 0.4757 & 0.1312 & 0.2240 & -0.1555 & -0.0889 & -0.0081 \\
\hline $22\left(D_{T 3}\right)$ & -0.5231 & 0.1135 & -0.0467 & -0.1013 & -0.0940 & 0.1615 & 0.0536 & 0.3091 & 0.1611 & 0.1881 \\
\hline Bias & -0.1355 & 0.2605 & 0.2510 & -0.3920 & 0.6944 & 0.2470 & 0.2161 & 0.2704 & -0.1449 & 0.3282 \\
\hline
\end{tabular}


Table A2. Weights between the hidden layer and the output layer in the MLP 22-10-3 artificial neural network.

\begin{tabular}{cccc}
\hline \multirow{2}{*}{ Hidden Layer } & \multicolumn{3}{c}{ Output Layer } \\
\cline { 2 - 4 } & $\mathbf{1}\left(F C_{U}\right)$ & $\mathbf{2}\left(\boldsymbol{F C} C_{H}\right)$ & $\mathbf{3}\left(\boldsymbol{F C} C_{M}\right)$ \\
\hline 1 & -1.1765 & -1.1077 & -0.9716 \\
2 & 0.2570 & -0.3898 & -0.0372 \\
3 & -0.4454 & -0.3606 & -0.3983 \\
4 & -0.8704 & -0.8448 & -0.8939 \\
5 & -0.1054 & -0.0468 & -0.0825 \\
6 & 0.2102 & 0.1440 & 0.1772 \\
7 & -0.5770 & -0.6157 & -0.5815 \\
8 & -0.2557 & -0.0877 & -0.1866 \\
9 & -1.1079 & -0.1888 & -0.6022 \\
10 & -0.4194 & -0.4122 & -0.4607 \\
Bias & 3.0602 & 2.3757 & 2.7454 \\
\hline
\end{tabular}

\section{Appendix B}

Weights of the synaptic pathways in the MLP 20-10-3 artificial neural network are presented in Tables A3 and A4.

Table A3. Weights between the input layer and hidden layer in the MLP 20-10-3 artificial neural network.

\begin{tabular}{|c|c|c|c|c|c|c|c|c|c|c|}
\hline \multirow{2}{*}{ Input Layer } & \multicolumn{10}{|c|}{ Hidden Layer } \\
\hline & 1 & 2 & 3 & 4 & 5 & 6 & 7 & 8 & 9 & 10 \\
\hline $1\left(D_{E}\right)$ & -1.6639 & -0.5427 & -0.6400 & -2.2715 & -0.3293 & -0.0143 & -1.4225 & 0.3937 & -0.2811 & -0.8970 \\
\hline $2\left(N_{C}\right)$ & -0.5674 & -1.0048 & -0.2679 & 0.0996 & -0.0824 & -0.6307 & -0.7623 & -0.6331 & -0.4103 & 0.3619 \\
\hline $3\left(N_{V}\right)$ & 0.5247 & 0.0188 & 0.4472 & -0.5617 & -0.0305 & 0.6609 & 0.4463 & 0.3168 & 0.5853 & -1.1059 \\
\hline $4\left(P_{M A X}\right)$ & 0.0755 & -1.8274 & 0.1991 & -0.3889 & -0.3997 & -0.3760 & 0.8215 & -1.1011 & -0.4183 & -2.1368 \\
\hline $5\left(T_{M A X}\right)$ & 0.6920 & 0.3141 & 0.4897 & 0.4168 & 0.1669 & 0.2526 & -0.0058 & 0.7507 & 0.1781 & -0.9557 \\
\hline $6\left(C_{R}\right)$ & 0.0159 & 2.7565 & 0.2241 & 0.3183 & 1.0543 & 0.3537 & 0.3164 & 0.3963 & 0.6138 & 0.3405 \\
\hline $7\left(W_{V}\right)$ & -0.0144 & 0.6246 & -1.0896 & 0.0063 & 0.0568 & -1.1912 & -0.6269 & -0.4642 & -0.5363 & -0.6934 \\
\hline $8\left(E_{T 1}\right)$ & -0.2732 & 0.0431 & -0.2841 & -0.1888 & -0.6847 & -0.0800 & -0.5504 & 0.4216 & -0.4343 & -0.2838 \\
\hline $9\left(E_{T 2}\right)$ & -0.3391 & -0.2746 & -0.1935 & -0.3192 & -0.4043 & 0.0845 & 0.6315 & -0.0058 & -0.1987 & 0.3312 \\
\hline $10\left(E_{T 3}\right)$ & 0.5250 & -0.0607 & 0.4576 & 0.1264 & 0.4614 & -0.5007 & -0.1404 & -0.7093 & 0.4074 & -0.2256 \\
\hline $11\left(E_{T 4}\right)$ & 0.5208 & -0.0179 & 0.6684 & 0.6342 & 0.1560 & 0.3443 & 0.4633 & 0.0942 & 0.0905 & 0.1696 \\
\hline $12\left(F_{I 1}\right)$ & 0.4634 & -0.3963 & 0.5690 & 0.7061 & -1.4592 & -0.2166 & 0.6892 & -1.1845 & -0.3073 & -0.4728 \\
\hline $13\left(F_{I 2}\right)$ & -0.0400 & 0.0486 & 0.1505 & -0.4326 & 1.0319 & 0.1433 & -0.3477 & 1.0755 & 0.2147 & 0.4304 \\
\hline $14\left(B_{T 1}\right)$ & 0.6902 & -0.1546 & 0.5649 & -0.4344 & 0.0590 & -0.2584 & 0.4335 & -0.5813 & 0.5127 & -1.0058 \\
\hline $15\left(B_{T 2}\right)$ & -0.0610 & 0.1546 & 0.2930 & 0.1795 & -0.2164 & -0.0684 & -0.1197 & 0.2826 & -0.3488 & 0.5950 \\
\hline $16\left(B_{T 3}\right)$ & -0.0225 & 0.1974 & -0.2008 & 0.3968 & -0.2358 & 0.1029 & -0.0708 & 0.3280 & -0.1172 & 0.1952 \\
\hline $17\left(B_{T 4}\right)$ & -0.1676 & -0.5538 & 0.0276 & 0.1746 & 0.0369 & 0.0677 & 0.1575 & -0.1782 & -0.0472 & 0.1863 \\
\hline $18\left(D_{T 1}\right)$ & 0.1071 & -0.2094 & 0.1963 & 0.3067 & -0.2461 & -0.1187 & -0.1024 & -0.2039 & 0.0837 & 0.4892 \\
\hline $19\left(D_{T 2}\right)$ & -0.1270 & 0.1834 & 0.0999 & -0.1648 & 0.0187 & 0.0880 & 0.3178 & -0.0097 & 0.1443 & 0.7366 \\
\hline $20\left(D_{\mathrm{T} 3}\right)$ & 0.5048 & -0.3027 & 0.3703 & 0.1241 & -0.1429 & -0.0232 & 0.1458 & 0.0309 & -0.2511 & -1.2196 \\
\hline Bias & 0.4652 & -0.3830 & 0.7129 & 0.2545 & -0.3994 & -0.1438 & 0.3726 & -0.1437 & -0.1077 & -0.0582 \\
\hline
\end{tabular}


Table A4. Weights between the hidden layer and the output layer in the MLP 22-10-3 artificial neural network.

\begin{tabular}{cccc}
\hline \multirow{2}{*}{ Hidden Layer } & \multicolumn{3}{c}{ Output Layer } \\
\cline { 2 - 4 } & $\mathbf{1}(\boldsymbol{F C} \boldsymbol{U})$ & $\mathbf{2}\left(\boldsymbol{F C} \boldsymbol{C}_{\boldsymbol{H}}\right)$ & $\mathbf{3}\left(\boldsymbol{F C _ { M } )}\right.$ \\
\hline 1 & -0.0978 & 0.1020 & -0.0372 \\
2 & 0.5263 & 0.3501 & 0.4651 \\
3 & -0.0622 & -0.2329 & -0.1141 \\
4 & -0.9635 & -0.5855 & -0.7522 \\
5 & -0.7370 & -0.0164 & -0.4454 \\
6 & 0.5206 & -1.2625 & -0.7602 \\
7 & -0.6456 & -0.3207 & -0.4459 \\
8 & -0.4761 & -0.2743 & -0.3227 \\
9 & -1.1609 & -1.1352 & -1.0552 \\
10 & -0.3650 & -0.3047 & -0.3596 \\
Bias & 2.6763 & 2.0268 & 2.3380 \\
\hline
\end{tabular}

\section{References}

1. Zhu, D.; Zheng, X. Fuel Consumption and Emission Characteristics in Asymmetric Twin-Scroll Turbocharged Diesel Engine with Two Exhaust Gas Recirculation Circuits. Appl. Energy 2019, 238, 985-995. [CrossRef]

2. Asher, Z.D.; Galang, A.A.; Briggs, W.; Johnston, B.; Bradley, T.H.; Jathar, S. Economic and Efficient Hybrid Vehicle Fuel Economy and Emissions Modeling Using an Artificial Neural Network; SAE Technical Paper 2018-01-0315; SAE: Warrenville, PA, USA, 2018; pp. 1-8. [CrossRef]

3. Wang, J.; Rakha, H.A. Fuel Consumption Model for Conventional Diesel Buses. Appl. Energy 2016, 170, 394-402. [CrossRef]

4. Zhang, Z.; Wei, L.; Lim, A. An Evolutionary Local Search for the Capacitated Vehicle Routing Problem Minimizing Fuel Consumption under Three-Dimensional Loading Constraints. Transp. Res. Part B Methodol. 2015, 82, 20-35. [CrossRef]

5. Macharis, C.; Van Hoeck, E.; Pekin, E.; van Lier, T. A Decision Analysis Framework for Intermodal Transport: Comparing Fuel Price Increases and the Internalisation of External Costs. Transp. Res. Part A Policy Pract. 2010, 44, 550-561. [CrossRef]

6. Elaiw, A.M.; Xia, X.; Shehata, A.M. Minimization of Fuel Costs and Gaseous Emissions of Electric Power Generation by Model Predictive Control. Math. Probl. Eng. 2013, 2013, 1-15. [CrossRef]

7. Lo, C.-L.; Chen, C.-H.; Kuan, T.-S.; Lo, K.-R.; Cho, H.-J. Fuel Consumption Estimation System and Method with Lower Cost. Symmetry 2017, 9, 105. [CrossRef]

8. Zargarnezhad, S.; Dashti, R.; Ahmadi, R. Predicting Vehicle Fuel Consumption in Energy Distribution Companies Using ANNs. Transp. Res. Part D Transp. Environ. 2019, 74, 174-188. [CrossRef]

9. Lasocki, J.; Boguszewski, K. Environmental Effects of Driving Style: Impact on Fuel Consumption. E3s Web Conf. 2019, 100, 8. [CrossRef]

10. Nutramon, T.; Supachart, C. Influence of Driving Cycles on Exhaust Emissions and Fuel Consumption of Gasoline Passenger Car in Bangkok. J. Environ. Sci. 2009, 21, 604-611. [CrossRef]

11. Wu, X.; Freese, D.; Cabrera, A.; Kitch, W.A. Electric Vehicles' Energy Consumption Measurement and Estimation. Transp. Res. Part D Transp. Environ. 2015, 34, 52-67. [CrossRef]

12. Yang, Z.; Liu, Y.; Wu, L.; Martinet, S.; Zhang, Y.; Andre, M.; Mao, H. Real-World Gaseous Emission Characteristics of Euro 6b Light-Duty Gasoline- and Diesel-Fueled Vehicles. Transp. Res. Part D Transp. Environ. 2020, 78, 1-11. [CrossRef]

13. Zamboni, G.; Moggia, S.; Capobianco, M. Hybrid EGR and Turbocharging Systems Control for Low NO and Fuel Consumption in an Automotive Diesel Engine. Appl. Energy 2016, 165, 839-848. [CrossRef]

14. D'Ambrosio, S.; Ferrari, A. Diesel Engines Equipped with Piezoelectric and Solenoid Injectors: Hydraulic Performance of the Injectors and Comparison of the Emissions, Noise and Fuel Consumption. Appl. Energy 2018, 211, 1324-1342. [CrossRef]

15. Galloni, E.; Fontana, G.; Palmaccio, R. Effects of Exhaust Gas Recycle in a Downsized Gasoline Engine. Appl. Energy 2013, 105, 99-107. [CrossRef]

16. Mao, B.; Yao, M.; Zheng, Z.; Liu, H. Effects of Dual Loop EGR and Variable Geometry Turbocharger on Performance and Emissions of a Diesel Engine; SAE International: Warrendale, PA, USA, 2016.

17. Dey, S.; Kamlu, S.; Mishra, S.K. Optimization of Fuel Consumption and Emission for Hybrid Electric Vehicle. Adv. Intell. Syst. Comput. 2016, 394, 715-722. [CrossRef]

18. Rakopoulos, C.D.; Antonopoulos, K.A.; Rakopoulos, D.C.; Hountalas, D.T.; Giakoumis, E.G. Comparative Performance and Emissions Study of a Direct Injection Diesel Engine Using Blends of Diesel Fuel with Vegetable Oils or Bio-Diesels of Various Origins. Energy Convers. Manag. 2006, 47, 3272-3287. [CrossRef]

19. Yao, Y.; Zhao, X.; Zhang, Y.; Chen, C.; Rong, J. Modeling of Individual Vehicle Safety and Fuel Consumption under Comprehensive External Conditions. Transp. Res. Part D Transp. Environ. 2020, 79. [CrossRef] 
20. Typaldos, P.; Papamichail, I.; Papageorgiou, M. Minimization of Fuel Consumption for Vehicle Trajectories. IEEE Trans. Intell. Transp. Syst. 2020, 21, 1716-1727. [CrossRef]

21. Khan, W.A.; Chung, S.-H.; Ma, H.-L.; Liu, S.Q.; Chan, C.Y. A Novel Self-Organizing Constructive Neural Network for Estimating Aircraft Trip Fuel Consumption. Transp. Res. Part E Logist. Transp. Rev. 2019, 132, 72-96. [CrossRef]

22. Tarelko, W.; Rudzki, K. Applying Artificial Neural Networks for Modelling Ship Speed and Fuel Consumption. Neural Comput. Applic. 2020, 32, 17379-17395. [CrossRef]

23. Le, L.T.; Lee, G.; Park, K.-S.; Kim, H. Neural Network-Based Fuel Consumption Estimation for Container Ships in Korea. Marit. Policy Manag. 2020, 47, 615-632. [CrossRef]

24. Gkerekos, C.; Lazakis, I.; Theotokatos, G. Machine Learning Models for Predicting Ship Main Engine Fuel Oil Consumption: A Comparative Study. Ocean Eng. 2019, 188, 106282. [CrossRef]

25. Jeon, M.; Noh, Y.; Shin, Y.; Lim, O.-K.; Lee, I.; Cho, D. Prediction of Ship Fuel Consumption by Using an Artificial Neural Network. J. Mech. Sci. Technol. 2018, 32, 5785-5796. [CrossRef]

26. Kee, K.-K.; Lau Simon, B.-Y.; Yong Renco, K.-H. Artificial Neural Network Back-Propagation Based Decision Support System for Ship Fuel Consumption Prediction. In Proceedings of the 5th IET International Conference on Clean Energy and Technology (CEAT2018), Kuala Lumpur, Malaysia, 5-6 September 2018; Volume 2018.

27. Du, Y.; Meng, Q.; Wang, S.; Kuang, H. Two-Phase Optimal Solutions for Ship Speed and Trim Optimization over a Voyage Using Voyage Report Data. Transp. Res. Part B Methodol. 2019, 122, 88-114. [CrossRef]

28. Siami-Irdemoosa, E.; Dindarloo, S.R. Prediction of Fuel Consumption of Mining Dump Trucks: A Neural Networks Approach. Appl. Energy 2015, 151, 77-84. [CrossRef]

29. Borges, P.H.M.; Mendoza, Z.M.S.H.; Maia, J.C.S.; Bianchini, A.; Fernándes, H.C. Estimation of Fuel Consumption in Agricultural Mechanized Operations Using Artificial Neural Networks. Eng. Agríc. 2017, 37, 136-147. [CrossRef]

30. Wysocki, O.; Deka, L.; Elizondo, D.; Kropiwnicki, J.; Czyżewicz, J. Heavy Duty Vehicle Fuel Consumption Modelling Based on Exploitation Data by Using Artificial Neural Networks. In Advances in Computational Intelligence; Rojas, I., Joya, G., Catala, A., Eds.; Springer: Cham, Switzerland, 2019; Volume 11506, pp. 794-805. [CrossRef]

31. Bera, P.; Pilch, R.; Szybka, J. Application of Neural Networks for Evaluation of the Fuel Consumption by Car. Czas. Tech. Tech. Trans. 2012, 14, 33-40.

32. Kara Togun, N.; Baysec, S. Prediction of Torque and Specific Fuel Consumption of a Gasoline Engine by Using Artificial Neural Networks. Appl. Energy 2010, 87, 349-355. [CrossRef]

33. Moradi, E.; Miranda-Moreno, L. Vehicular Fuel Consumption Estimation Using Real-World Measures through Cascaded Machine Learning Modeling. Transp. Res. Part D Transp. Environ. 2020, 88, 102576. [CrossRef]

34. Du, Y.; Wu, J.; Yang, S.; Zhou, L. Predicting Vehicle Fuel Consumption Patterns Using Floating Vehicle Data. J. Environ. Sci. 2017, 59, 24-29. [CrossRef] [PubMed]

35. Babu, D.; Thangarasu, V.; Ramanathan, A. Artificial Neural Network Approach on Forecasting Diesel Engine Characteristics Fuelled with Waste Frying Oil Biodiesel. Appl. Energy 2020, 263, 114612. [CrossRef]

36. Bhowmik, S.; Paul, A.; Panua, R.; Ghosh, S.K.; Debroy, D. Performance-Exhaust Emission Prediction of Diesosenol Fueled Diesel Engine: An ANN Coupled MORSM Based Optimization. Energy 2018, 153, 212-222. [CrossRef]

37. Parlak, A.; Islamoglu, Y.; Yasar, H.; Egrisogut, A. Application of Artificial Neural Network to Predict Specific Fuel Consumption and Exhaust Temperature for a Diesel Engine. Appl. Therm. Eng. 2006, 26, 824-828. [CrossRef]

38. Roy, S.; Banerjee, R.; Bose, P.K. Performance and Exhaust Emissions Prediction of a CRDI Assisted Single Cylinder Diesel Engine Coupled with EGR Using Artificial Neural Network. Appl. Energy 2014, 119, 330-340. [CrossRef]

39. Hosamani, B.R.; Abbas Ali, S.; Katti, V. Assessment of Performance and Exhaust Emission Quality of Different Compression Ratio Engine Using Two Biodiesel Mixture: Artificial Neural Network Approach. Alex. Eng. J. 2021, 60, 837-844. [CrossRef]

40. Jaliliantabar, F.; Ghobadian, B.; Najafi, G.; Yusaf, T. Artificial Neural Network Modeling and Sensitivity Analysis of Performance and Emissions in a Compression Ignition Engine Using Biodiesel Fuel. Energies 2018, 11, 2410. [CrossRef]

41. Toghyani, S.; Ahmadi, M.H.; Kasaeian, A.; Mohammadi, A.H. Artificial Neural Network, ANN-PSO and ANN-ICA for Modelling the Stirling Engine. Int. J. Ambient Energy 2016, 37, 456-468. [CrossRef]

42. Jiang, H.; Xi, Z.; Rahman, A.A.; Zhang, X. Prediction of Output Power with Artificial Neural Network Using Extended Datasets for Stirling Engines. Appl. Energy 2020, 271, 115123. [CrossRef]

43. Mehra, R.K.; Duan, H.; Luo, S.; Rao, A.; Ma, F. Experimental and Artificial Neural Network (ANN) Study of Hydrogen Enriched Compressed Natural Gas (HCNG) Engine under Various Ignition Timings and Excess Air Ratios. Appl. Energy 2018, 228, 736-754. [CrossRef]

44. Qi, X.; Wu, G.; Boriboonsomsin, K.; Barth, M.J. Data-Driven Decomposition Analysis and Estimation of Link-Level Electric Vehicle Energy Consumption under Real-World Traffic Conditions. Transp. Res. Part D Transp. Environ. 2018, 64, 36-52. [CrossRef]

45. Karlaftis, M.G.; Vlahogianni, E.I. Statistical Methods versus Neural Networks in Transportation Research: Differences, Similarities and Some Insights. Transp. Res. Part C Emerg. Technol. 2011, 19, 387-399. [CrossRef]

46. Cai, M.; Yin, Y.; Xie, M. Prediction of Hourly Air Pollutant Concentrations near Urban Arterials Using Artificial Neural Network Approach. Transp. Res. Part D Transp. Environ. 2009, 14, 32-41. [CrossRef]

47. Chang, J.; Tseng, C. Analysis of Correlation Between Secondary PM2.5 and Factory Pollution Sources by Using ANN and the Correlation Coefficient. IEEE Access 2017, 5, 22812-22822. [CrossRef] 
48. Zeng, T.; Zhang, C.; Hu, M.; Chen, Y.; Yuan, C.; Chen, J.; Zhou, A. Modelling and Predicting Energy Consumption of a Range Extender Fuel Cell Hybrid Vehicle. Energy 2018, 165, 187-197. [CrossRef]

49. De Cauwer, C.; Van Mierlo, J.; Coosemans, T. Energy Consumption Prediction for Electric Vehicles Based on Real-World Data. Energies 2015, 8, 8573-8593. [CrossRef]

50. Kędzierski, P.; Morka, A.; Stanisławek, S.; Surma, Z. Numerical Modeling of the Large Strain Problem in the Case of Mushrooming Projectiles. Int. J. Impact Eng. 2020, 135, 103403. [CrossRef]

51. Cheng, X.; Li, G.; Skulstad, R.; Chen, S.; Hildre, H.P.; Zhang, H. A Neural-Network-Based Sensitivity Analysis Approach for Data-Driven Modeling of Ship Motion. IEEE J. Ocean. Eng. 2020, 45, 451-461. [CrossRef]

52. Mrzygłód, B.; Hawryluk, M.; Janik, M.; Olejarczyk-Wożeńska, I. Sensitivity Analysis of the Artificial Neural Networks in a System for Durability Prediction of Forging Tools to Forgings Made of C45 Steel. Int. J. Adv. Manuf. Technol. 2020, 109, 1385-1395. [CrossRef]

53. Gajewski, J.; Sadowski, T. Sensitivity Analysis of Crack Propagation in Pavement Bituminous Layered Structures Using a Hybrid System Integrating Artificial Neural Networks and Finite Element Method. Comput. Mater. Sci. 2014, 82, 114-117. [CrossRef]

54. Park, Y.; Choi, M.; Kim, K.; Li, X.; Jung, C.; Na, S.; Choi, G. Prediction of Operating Characteristics for Industrial Gas Turbine Combustor Using an Optimized Artificial Neural Network. Energy 2020, 213, 118769. [CrossRef]

55. Zhang, G.; Patuwo, E.B.; Hu, M.Y. Forecasting with Artificial Neural Networks. Int. J. Forecast. 1998, 14, 35-62. [CrossRef]

56. Cui, Z.; Ke, R.; Pu, Z.; Ma, X.; Wang, Y. Learning Traffic as a Graph: A Gated Graph Wavelet Recurrent Neural Network for Network-Scale Traffic Prediction. Transp. Res. Part C Emerg. Technol. 2020, 115, 102620. [CrossRef]

57. Yao, J.; Moawad, A. Vehicle Energy Consumption Estimation Using Large Scale Simulations and Machine Learning Methods. Transp. Res. Part C Emerg. Technol. 2019, 101, 276-296. [CrossRef]

58. Chen, Y.; Zhu, L.; Gonder, J.; Young, S.; Walkowicz, K. Data-Driven Fuel Consumption Estimation: A Multivariate Adaptive Regression Spline Approach. Transp. Res. Part C Emerg. Technol. 2017, 83, 134-145. [CrossRef]

59. Zheng, Q.; Tian, S.; Zhang, Q. Optimal Torque Split Strategy of Dual-Motor Electric Vehicle Using Adaptive Nonlinear Particle Swarm Optimization. Math. Probl. Eng. 2020, 2020, 1-21. [CrossRef]

60. Fernández-Yáñez, P.; Armas, O.; Martínez-Martínez, S. Impact of Relative Position Vehicle-Wind Blower in a Roller Test Bench under Climatic Chamber. Appl. Therm. Eng. 2016, 106, 266-274. [CrossRef]

61. Marotta, A.; Pavlovic, J.; Ciuffo, B.; Serra, S.; Fontaras, G. Gaseous Emissions from Light-Duty Vehicles: Moving from NEDC to the New WLTP Test Procedure. Environ. Sci. Technol. 2015, 49, 8315-8322. [CrossRef]

62. Montazeri, M.; Fotouhi, A.; Naderpour, A. Driving Segment Simulation for Determination of the Most Effective Driving Features for HEV Intelligent Control. Veh. Syst. Dyn. 2012, 50, 229-246. [CrossRef]

63. Miri, I.; Fotouhi, A.; Ewin, N. Electric Vehicle Energy Consumption Modelling and Estimation-A Case Study. Int. J. Energy Res. 2021, 45, 501-520. [CrossRef] 